University of Nebraska - Lincoln DigitalCommons@University of Nebraska - Lincoln

James Van Etten Publications

Plant Pathology Department

$5-2017$

\title{
Identification of Intrahelical Bifurcated H-Bonds as a New Type of Gate in K+ Channels
}

Oliver Rauh

Martin Urban

Leonhard M. Henkes

Tobias Winterstein

Timo Greiner

See next page for additional authors

Follow this and additional works at: https://digitalcommons.unl.edu/vanetten

Part of the Genetics and Genomics Commons, Plant Pathology Commons, and the Viruses Commons

This Article is brought to you for free and open access by the Plant Pathology Department at DigitalCommons@University of Nebraska - Lincoln. It has been accepted for inclusion in James Van Etten Publications by an authorized administrator of DigitalCommons@University of Nebraska - Lincoln. 
Authors

Oliver Rauh, Martin Urban, Leonhard M. Henkes, Tobias Winterstein, Timo Greiner, James L. Van Etten, Anna Moroni, Stefan M. Kast, Gerhard Thiel, and Indra Schroeder 


\title{
Identification of Intrahelical Bifurcated H-Bonds as a New Type of Gate in $\mathrm{K}^{+}$Channels
}

\author{
Oliver Rauh, ${ }^{\dagger}$ Martin Urban, $^{\dagger}$ Leonhard M. Henkes, $^{\ddagger}$ Tobias Winterstein, $^{\dagger}$ Timo Greiner, ${ }^{\dagger}$
} James L. Van Etten, ${ }^{\S}$ Anna Moroni, ${ }^{\|}$Stefan M. Kast, ${ }^{\ddagger 0}$ Gerhard Thiel, ${ }^{*}{ }^{\dagger}(0)$ and Indra Schroeder ${ }^{\dagger}$

${ }^{\dagger}$ Plant Membrane Biophysics, Technical University Darmstadt, 64289 Darmstadt, Germany

${ }^{\ddagger}$ Physikalische Chemie III, Technische Universität Dortmund, 44227 Dortmund, Germany

${ }^{\S}$ Department of Plant Pathology and Nebraska Center for Virology, University of Nebraska Lincoln, Lincoln, Nebraska 68583-0900, United States

"Department of Biosciences and CNR IBF-Mi, Università degli Studi di Milano, 20122 Milano, Italy

\section{Supporting Information}

ABSTRACT: Gating of ion channels is based on structural transitions between open and closed states. To uncover the chemical basis of individual gates, we performed a comparative experimental and computational analysis between two $\mathrm{K}^{+}$channels, $\mathrm{Kcv}_{\mathrm{S}}$ and $\mathrm{Kcv}_{\mathrm{NTS}}$. These small viral encoded $\mathrm{K}^{+}$ channel proteins, with a monomer size of only 82 amino acids, resemble the pore module of all complex $\mathrm{K}^{+}$channels in terms of structure and function. Even though both proteins share about $90 \%$ amino acid sequence identity, they exhibit different open probabilities with ca. $90 \%$ in $\mathrm{Kcv}_{\mathrm{NTS}}$ and $40 \%$ in $\mathrm{Kcv}_{\mathrm{S}}$. Single channel analysis, mutational studies and molecular dynamics simulations show that the difference in open probability is caused by one long closed state in $\mathrm{Kcv}_{S}$. This state is structurally created in the tetrameric

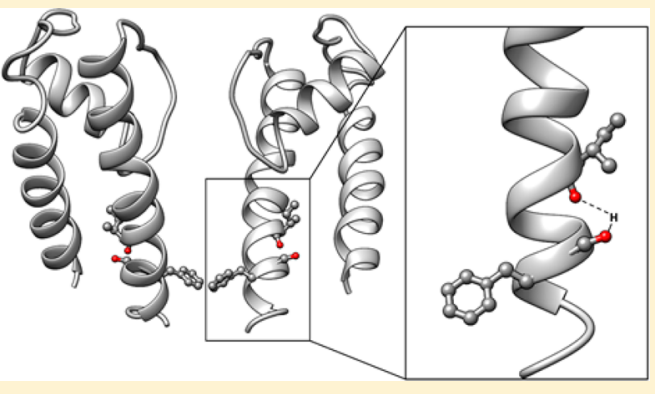
channel by a transient, Ser mediated, intrahelical hydrogen bond. The resulting kink in the inner transmembrane domain swings the aromatic rings from downstream Phes in the cavity of the channel, which blocks ion flux. The frequent occurrence of Ser or Thr based helical kinks in membrane proteins suggests that a similar mechanism could also occur in the gating of other ion channels.

\section{INTRODUCTION}

Ion channels fluctuate stochastically between conductive "open" states and nonconductive "closed" states. ${ }^{1}$ This process of gating determines the flux of ions across membranes and is therefore a crucial parameter for the regulation of channel activity in the physiological context. Many physical factors like voltage or mechanical stretch and chemical factors like ligands or signaling molecules can modulate the stability of individual closed or open states and as a consequence regulate ion fluxes across membranes. The recent availability of high-resolution structures of channel proteins makes it possible to correlate experimentally measured gating events from single channel recordings with dynamic structural phenomena., ${ }^{2,3}$ Well documented correlations between channel gating and structural modifications are known from the model $\mathrm{K}^{+}$channel KcsA. Two gates have been identified in this channel. One gate is located at the inner bundle crossing and is activated by $\mathrm{H}^{+}$. The second gate is in the selectivity filter. Additional structure/ function studies have uncovered some electrostatic interactions among amino acid (AA) side chains, which are presumably responsible for the stochastic switching between open and closed states of the channel. For the $\mathrm{H}^{+}$dependent gating in the KcsA channel a complex network of inter- and intrasubunit salt bridges and hydrogen bonds were identified near the bundle crossing; these are stabilized or destabilized according to $\mathrm{pH}^{3}$ In the case of the KcsA filter gate a network of AA side chains surrounding the selectivity filter together with the ions in the filter and water behind the filter affect the stability of the conformational states of the pore. A key role in this network is played by a single carboxyl-carboxylate interaction between a Glu (E71) in the pore helix and an Asp (D80) in the signature sequence. Substitution of E71 with Ala (E71A) led to a complete disappearance of inactivation and a constitutively open channel at low $\mathrm{pH}^{2}$

Here we use small chlorovirus encoded $\mathrm{K}^{+}$channels to search for additional structural motives for ion channel gating. These channels, which represent the pore module of complex $\mathrm{K}^{+}$ channels, ${ }^{4}$ have the advantage of being truly minimal because they consist of two transmembrane domains, a pore loop, short $\mathrm{N}$ and $\mathrm{C}$ termini and small extracellular loops (Figure 1a). Like other $\mathrm{K}^{+}$channels they form functional tetramers and have many functional properties present in more complex $\mathrm{K}^{+}$ channels. These properties include $\mathrm{K}^{+}$selectivity, a susceptibility to blockers and, important for this study, stochastic gating between defined open and closed states. ${ }^{5,6}$ By using $\mathrm{K}^{+}$channel

Received: February 3, 2017

Published: May 12, 2017 
a

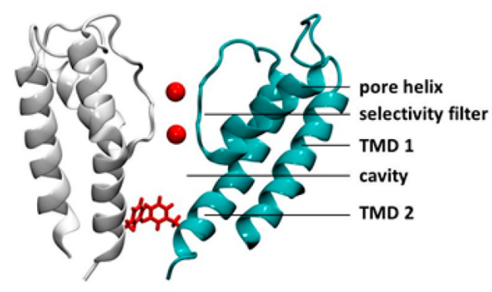

b

$\mathrm{KCV}_{\mathrm{S}}$

$\mathrm{KCV}_{\mathrm{NTS}}$

$\mathrm{KCV}_{\mathrm{ATCV}-1}$

$\mathrm{KCV}_{\mathrm{S}}$

$\mathrm{KCV}_{\text {NTS }}$

$\mathrm{KCV}_{\mathrm{ATCV}-1}$

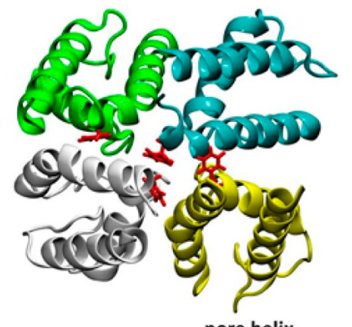

pore helix MLLLLIHVGILVFFTTVYKMLPGGMFSNTDPSWVDCLYFSA MLLLIIHLSILVIFTA IYKMLPGGMESNTDPTWVDCLYFSA 41 MLLLI IHI I ILIVFTAIYKMLPGGMFSNTDPTWVDCLYFSA 41 MLLLIIHIIIIVTAIYKMPGGMFSNTDPTWDCLYFSA TMD 2

$\overline{\text { STHTTVGYGDLTPKS PVAKLVATAHMMIVFAIVVSSFTFPW }} 82$ STHTTVGYGDLTPKSPVAKLTATAHMLIVFAIVISGFTFPW 82 STHTTVGYGDLTPKSPVAKLTATAHMLIVFAIVISGFTFPW 82 $* * * * * * * * * * * * * * * * * * * *, * * * * *: * * * * * *: * * * * * * *$

Figure 1. Chlorovirus encoded $\mathrm{K}^{+}$channels. (a) Cartoon representations of a snapshot of $\mathrm{Kcv}_{\mathrm{S}}$ taken from MD simulation at $80 \mathrm{~ns}$ of the production run. Left: Side view of the channel (two opposing monomer units). Right: view from bottom to top of the full tetrameric channel. Potassium ions are shown as red spheres, and F78 as explicit side chains in red. (b) Sequence alignment of three viral encoded $\mathrm{K}^{+}$ channels. The position of the transmembrane domains TMD1 and TMD2 as well as the pore helix are indicated by bars. The sequences are $86 \%$ identical; amino acid differences are highlighted in gray.

genes from chloroviruses isolated from different environments we have created a large library of structural orthologs, which exhibit distinct functional differences. ${ }^{7,8}$ In the present study we analyzed two small $\mathrm{K}^{+}$channel orthologs, which differ in the presence or absence of a long-lived closed state, even though they have high AA identity. Comparative analysis of the two channels identified a Phe in the inner transmembrane helix as a gate, which can obstruct the ion pathway in the cavity. The stochastic insertion and removal of the hydrophobic barrier is achieved by the formation of H-bonds between an adjacent Ser with upstream-positioned AAs in the transmembrane helix. Hence stochastic gating of this long-lived closed state presumably reflects the formation of a kink in the inner transmembrane helix. This in turn causes an orientation of the Phe in the ionic pathway where it functions as a barrier of ion flux.

\section{RESULTS AND DISCUSSION}

Two Similar Channels with Different Open Probabilities. The viral encoded proteins $\mathrm{Kcv}_{\mathrm{NTS}}$ and $\mathrm{Kcv}_{\mathrm{S}}$ are small $\mathrm{K}^{+}$channels with only 82 AAs per monomer. The two proteins differ in 11 AAs of which 8 are conservative and 3 are semiconservative exchanges (Figure $1 \mathrm{~b}$ ). The difference between $\mathrm{Kcv}_{\mathrm{NTS}}$ and a third channel $\mathrm{Kcv}_{\mathrm{ATCV}-1}$, which was analyzed previously, ${ }^{9}$ is only four AAs. When reconstituted in planar lipid bilayers, $\mathrm{Kcv}_{\mathrm{NTS}}$ and $\mathrm{Kcv}_{\mathrm{S}}$ generated channel fluctuations with a similar unitary conductance and the same characteristic $i / V$ relation (Figure $2 a-c$ ). The latter is characterized by an Ohmic conductance at positive voltages and a negative slope conductance at negative voltages. The decrease in channel amplitude at negative voltages is caused by a rapid flickering of the channel, which results in unresolved channel openings (Figure 2a,b). ${ }^{6}$ These recordings imply that

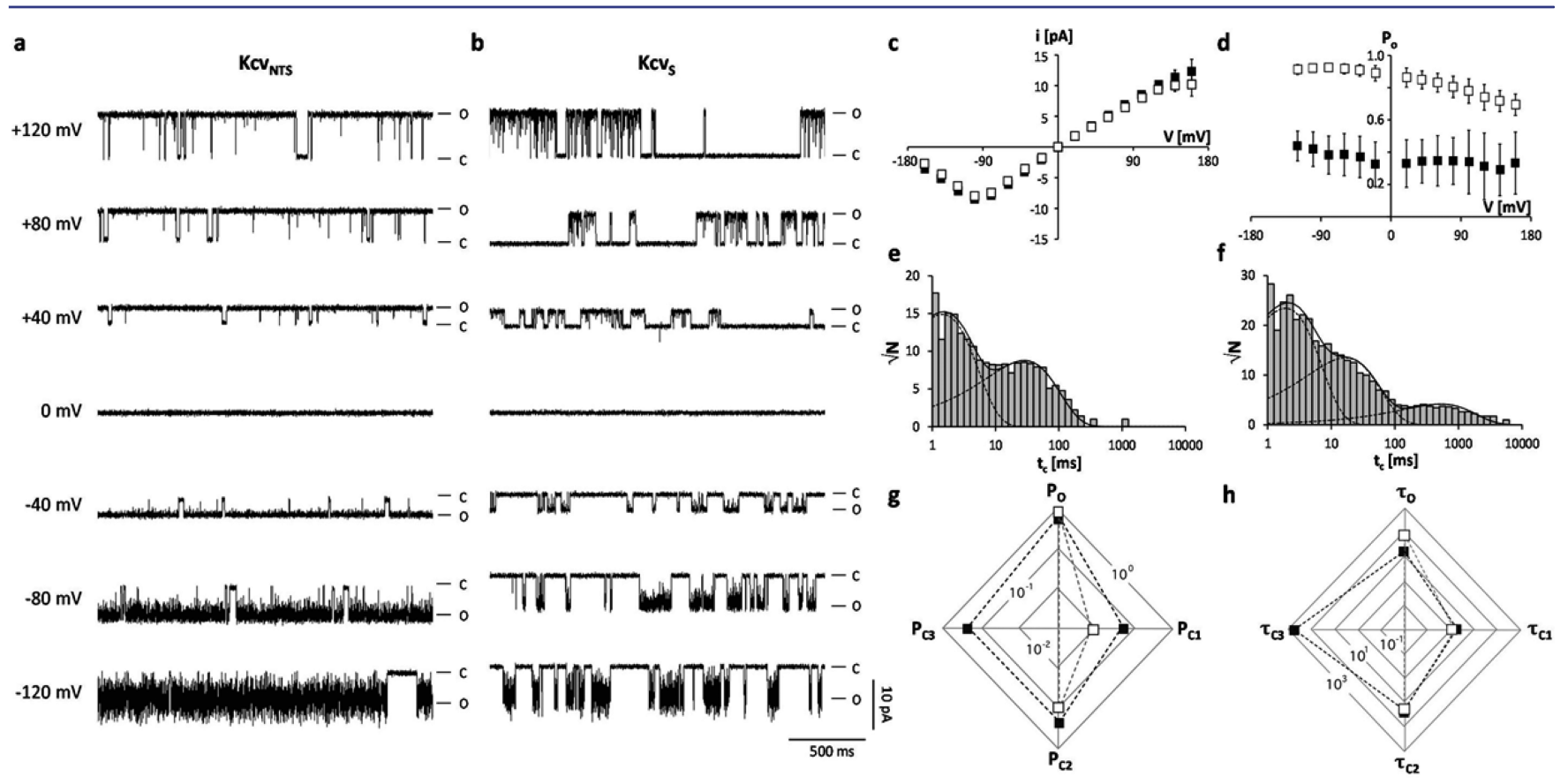

Figure 2. The difference in open probability of two similar $\mathrm{K}^{+}$channels originates from a long closed time, which is absent in $\mathrm{Kcv}_{\mathrm{NTS}}$ and present in $\mathrm{Kcv}_{\mathrm{S}}$. (a,b) Characteristic single channel fluctuations of $\mathrm{Kcv}_{\mathrm{NTS}}$ and $\mathrm{Kcv}_{\mathrm{S}}$ at different voltages in a planar lipid bilayer. The closed (C) and open (O) levels are indicated along the current traces. (c) Mean single channel $i / V$ relations ( $\pm \mathrm{sd}$ ) of $\mathrm{Kcv}_{\mathrm{NTS}}$ (open squares) and $\mathrm{Kcv}_{\mathrm{S}}$ (filled squares) from 6 and 9 independent recordings, respectively. (d) Mean open probabilities ( \pm sd) of the two channels from 6 and 9 independent recordings. Exemplary closed dwell times at $+120 \mathrm{mV}$ for $\mathrm{Kcv}_{\mathrm{NTS}}(\mathrm{e})$ and $\mathrm{Kcv}_{\mathrm{S}}$ (f). The data in e can be fitted with two exponentials while the data in $\mathrm{f}$ require a third exponential. The long-lived closed state in $\mathrm{f}$ is absent in e. The multiple kinetic variables of the two channels including the probabilities ( $\mathrm{P}$ ) for occupying the open state $(\mathrm{O})$ and the closed states $(\mathrm{C} 1-\mathrm{C} 3)(\mathrm{g})$ as well as mean lifetimes $($ in $\mathrm{ms})$ of the open state $\left(\tau_{\mathrm{o}}\right)$ and of the three closed states $\left(\tau_{\mathrm{c} 1}-\tau_{\mathrm{c} 3}\right)(\mathrm{h})$ are presented in two-dimensional radar plots. The probabilities of occupancy and mean lifetimes were calculated from three independent $5 \mathrm{~min}$ recordings. The symbols in $\mathrm{d}, \mathrm{g}$ and $\mathrm{h}$ correspond to those in $\mathrm{c}$. 
the AA deviations between the two channels have no large impact on the unitary conductance and on fast gating, which is presumably dominated by a selectivity filter gate. ${ }^{6}$

In spite of the sequence similarity, the two channels differed significantly in their open probability $\left(P_{\mathrm{o}}\right)$ (Figure 2a,b,d). While $\mathrm{Kcv}_{\mathrm{NTS}}$ showed robust high $P_{\mathrm{o}}$ values of $0.84 \pm 0.08$ over the entire voltage window, $\mathrm{Kcv}_{\mathrm{S}}$ exhibited a much lower open probability of only $0.35 \pm 0.04$. Comparative analysis of the open and closed dwell times showed that the two channels differed mainly in one distinct parameter namely a long closed time $\tau_{\mathrm{C} 3}$, which was absent in $\mathrm{Kcv}_{\mathrm{NTS}}$ (Figure 2e,g) but present and frequently occurred in $\mathrm{Kcv}_{\mathrm{S}}$ (Figure $2 \mathrm{f}, \mathrm{g}$ ). The two channels also exhibited a difference in the mean open dwell times, which are at $+120 \mathrm{mV} 79 \pm 19 \mathrm{~ms}$ and $15 \pm 3 \mathrm{~ms}$ for $\mathrm{Kcv}_{\mathrm{NTS}}$ and $\mathrm{Kcv}_{\mathrm{S}}$, respectively (Figure S1, Table S1). This difference is caused by variable probabilities/rate constants with which the channel fluctuates between the open state and the first, short closed state $(\mathrm{C} 1)$. The associated closing frequency has however only a marginal effect on $P_{\mathrm{o}}$. The mean lifetime $\tau_{\mathrm{C} 1}$ of the first closed state $(1.3 \pm 0.2 \mathrm{~ms}$ and $1.8 \pm 0.8 \mathrm{~ms}$ at +120 $\mathrm{mV}$ for $\mathrm{Kcv}_{\mathrm{NTS}}$ and $\mathrm{Kcv}_{\mathrm{S}}$, respective) is so short that it hardly affects $P_{\mathrm{o}}$ (Figure 2g,h, Table $\mathrm{S} 1$ ). The low open probability of $\mathrm{Kcv}_{\mathrm{S}}$ is therfore primarily the result of the long lasting closed events $\left(\tau_{\mathrm{C} 3}\right)$ with a mean lifetime of $480 \pm 145 \mathrm{~ms}$ at $+120 \mathrm{mV}$ (Figure 2h, Table S1).

From these data we conclude that the high sequence similarity and the fact that the two channels differ in one defined closed state make their comparative analysis an ideal system for studying the molecular basis of a channel gate. Since the different AAs are distributed over the two transmembrane domains (TMDs) (Figure 1b) we first tackled the location of the gate, which is responsible for the long closed time. To this end, chimeras were generated, in which we swapped the two TMDs (Figure 3a). Figure $3 \mathrm{~b}$ shows that both chimeras produced channel activity with the same unitary conductance (Figure 3c) but with distinct kinetics.

It appears that the exchange of the two TMDs led to a reverse gating characteristics: $\mathrm{Kcv}_{\mathrm{NTS} / \mathrm{S}}$ now shows the long closed state and low $P_{\mathrm{o}}$ whereas $\mathrm{Kcv}_{\mathrm{S} / \mathrm{NTS}}$ acquires a high $P_{\mathrm{o}}$ and only short closings (Figure $3 \mathrm{~b}-\mathrm{h}$, Table $\mathrm{S} 1$ ). From the results of these experiments we conclude that the structural information, which is responsible for the long closed time, is located in TMD2. Also TMD1 must have some impact on channel gating, but this contribution is not relevant for the long closed time.

Ser77 and Phe78 Are Crucial for Long-Lived Closed State. There are only four AA differences between the TMD2 of $\mathrm{Kcv}_{\mathrm{NTS}}$ and $\mathrm{Kcv}_{\mathrm{S}}$. To identify the relevant AA in TMD2 for gating we mutated all 4 candidates in $\mathrm{Kcv}_{\mathrm{NTS}}$ into the respective residue of $\mathrm{Kcv}_{S}$. A functional analysis of the mutants showed that mutations $\mathrm{T} 62 \mathrm{~V}, \mathrm{~L} 68 \mathrm{M}$, and $\mathrm{I} 75 \mathrm{~V}$ in $\mathrm{Kcv}_{\mathrm{NTS}}$ had no impact on gating (Figure S2). Only the mutual exchange of $S$ and $\mathrm{G}$ at position 77 in $\mathrm{Kcv}_{\mathrm{NTS}}$ and $\mathrm{Kcv}_{\mathrm{S}}$ completely inverted the gating properties of the two channels: the $\mathrm{Kcv}_{\mathrm{S}} \mathrm{S} 77 \mathrm{G}$ mutant acquired the high open probability of $\mathrm{Kcv}_{\mathrm{NTS}}$ and the open probability of $\mathrm{Kcv}_{\mathrm{NTS}} \mathrm{G} 77 \mathrm{~S}$ decreased to that of $\mathrm{Kcv}_{\mathrm{S}}$ (Figure $4 \mathrm{a}, \mathrm{b}, \mathrm{d}$ ). The impact of the mutations on $P_{\mathrm{o}}$ can be explained by the disappearance of the long closed time in $\mathrm{Kcv}_{S}$ S77G and its appearance in $\mathrm{Kcv}_{\mathrm{NTS}}$ G77S (Figure $4 \mathrm{e}-\mathrm{h}$, Table S1).

We reasoned that due to their small size neither the AA Gly nor Ser at position 77 could be a gate, which could by itself obstruct the flow of ions. Scrutiny of the channel sequences
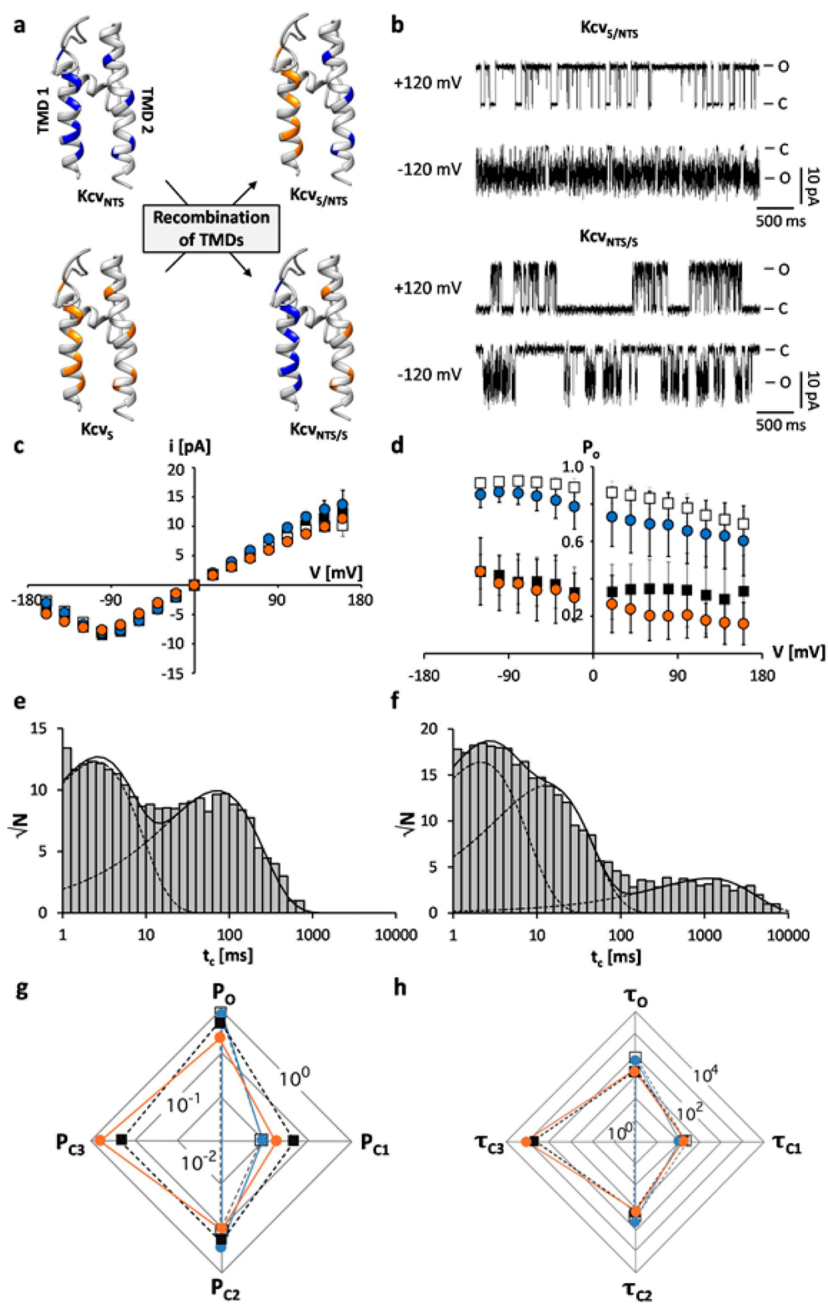

Figure 3. The $\mathrm{Kcv}_{S}$ long closed time is related to TMD2. (a) Chimeras were constructed by swapping transmembrane domains between $\mathrm{Kcv}_{\mathrm{NTS}}$ (in blue) and $\mathrm{Kcv}_{\mathrm{S}}$ (orange), for illustration purposes only. (b) Characteristic single channel fluctuations of chimeras $\mathrm{Kcv}_{\mathrm{S} / \mathrm{NTS}}$ and $\mathrm{Kcv}_{\mathrm{NTS} / \mathrm{s}}$ at $\pm 120 \mathrm{mV}$ in planar lipid bilayers. (c) Mean single channel $i / V$ relations ( \pm sd) of $\mathrm{Kcv}_{\mathrm{NTS}}$ (open squares), $\mathrm{Kcv}_{\mathrm{S}}$ (filled squares), $\mathrm{Kcv}_{\mathrm{S} / \mathrm{NTS}}$ (blue circles, $n=9$ ) and $\mathrm{Kcv}_{\mathrm{NTS} / \mathrm{S}}$ (orange circles, $n=3$ ). (d) Mean open probabilities $( \pm \mathrm{sd})$ of wt channels and chimeras $(n=9$ and $n=3$ for $\mathrm{Kcv}_{\mathrm{S} / \mathrm{NTS}}$ and $\mathrm{Kcv}_{\mathrm{NTS} / \mathrm{S}}$, respectively). Exemplary closed dwell times at $+120 \mathrm{mV}$ for $\mathrm{Kcv}_{\mathrm{S} / \mathrm{NTS}}(\mathrm{e})$ and $\mathrm{Kcv}_{\mathrm{NTS} / \mathrm{S}}$ (f). The data in e can be fitted with two exponentials while the data in $\mathrm{f}$ require a third exponential. Radar plots for probabilities (P) of the wt channels and the chimeras for occupying the open state $(\mathrm{O})$ and the closed states $(\mathrm{C} 1-\mathrm{C} 3)(\mathrm{g})$ and of mean lifetimes (in ms) of the open state $\left(\tau_{\mathrm{o}}\right)$ and of the three closed states $\left(\tau_{\mathrm{c} 1}-\tau_{\mathrm{c} 3}\right)(\mathrm{h})$. The probabilities of occupancy and mean lifetimes were calculated from three independent $5 \mathrm{~min}$ recordings. The symbols in $\mathrm{d}, \mathrm{g}$ and $\mathrm{h}$ correspond to those in $\mathrm{c}$.

however revealed that the next AA downstream of position 77 was the aromatic AA Phe in both channels (F78). We predicted that the Phe aromatic side chain was positioned in or out of the ion pathway, depending on the nature of the adjacent AA. To test if F78 had any influence on the gating of the two channels we mutated it to an Ala in $\mathrm{Kcv}_{S}$. The data show that removal of the aromatic side chain in the $\mathrm{Kcv}_{\mathrm{S}}$ channel resulted in an increase in open probability and the disappearance of the long closed state C3 (Figure 5a,d,e,g,h, Table S1). To further test the hypothesis that F78 is a gate in combination with the adjacent $\mathrm{AA}$ we constructed the double mutant $\mathrm{Kcv}_{\mathrm{NTS}}$ G77S F78A. A functional test of this mutant showed that replacement 

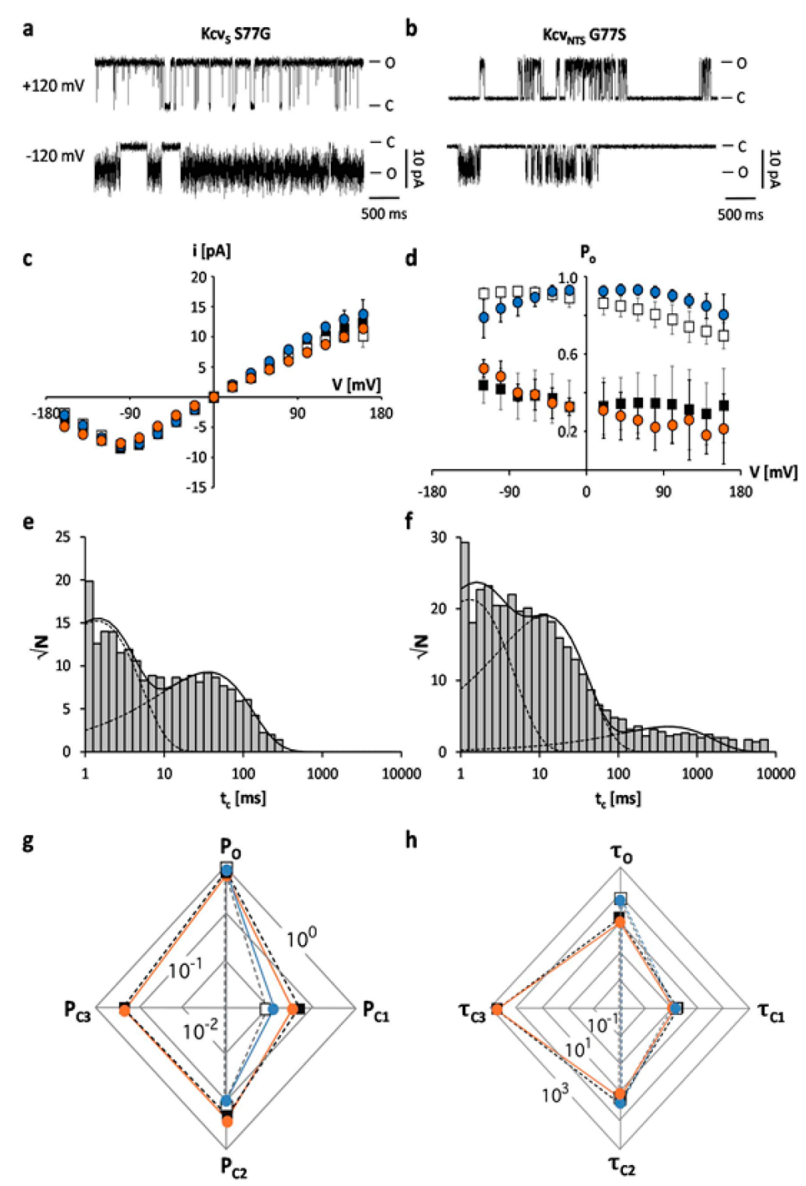

Figure 4. The difference of $\mathrm{Kcv}_{\mathrm{NTS}}$ and $\mathrm{Kcv}_{\mathrm{S}}$ in position 77 is responsible for the absence or presence of a long closed time. Characteristic single channel fluctuations of mutant $\mathrm{Kcv}_{\mathrm{S}} \mathrm{S} 77 \mathrm{G}$ (a) and $\mathrm{Kcv}_{\mathrm{NTS}} \mathrm{G} 77 \mathrm{~S}$ (b) at $\pm 120 \mathrm{mV}$ in planar lipid bilayers. (c) Mean single channel $i / V$ relations ( \pm sd) of $\mathrm{Kcv}_{\mathrm{NTS}}$ (open squares), $\mathrm{Kcv}_{\mathrm{S}}$ (filled squares), $\mathrm{Kcv}_{\mathrm{NTS}} \mathrm{G} 77 \mathrm{~S}$ (orange circles, $n=5$ ) and $\mathrm{Kcv}_{\mathrm{S}}$ S77G (blue circles, $n=3$ ). (d) Mean open probabilities ( \pm sd) of wt channels and mutants $\left(n=5\right.$ and $n=3$ for $\mathrm{Kcv}_{\mathrm{NTS}}$ G77S and $\mathrm{Kcv}_{\mathrm{S}}$ S77G, respectively). Exemplary closed dwell times at $+120 \mathrm{mV}$ for $\mathrm{Kcv}_{\mathrm{S}} \mathrm{S} 77 \mathrm{G}$ (e) and $\mathrm{Kcv}_{\mathrm{NTS}} \mathrm{G} 77 \mathrm{~S}$ (f). The data in e can be fitted with two exponentials while the data in $\mathrm{f}$ again require a third exponential. Radar plots for probabilities (P) of the wt channels and mutants for occupying the open state $(\mathrm{O})$ and the closed states $(\mathrm{C} 1-\mathrm{C} 3)(\mathrm{g})$ and for mean lifetimes (in ms) of the open state $\left(\tau_{\mathrm{o}}\right)$ and of the three closed states $\left(\tau_{\mathrm{c1}}-\tau_{\mathrm{c} 3}\right)(\mathrm{h})$. The probabilities of occupancy and mean lifetimes were calculated from three independent $5 \mathrm{~min}$ recordings. The symbols in $\mathrm{d}, \mathrm{g}$ and $\mathrm{h}$ correspond to those in $\mathrm{c}$.

of the aromatic AA neutralized the effect of the G77S mutation (Figure $5 \mathrm{~b}, \mathrm{~d}, \mathrm{f}-\mathrm{h}, \mathrm{Table} \mathrm{S} 1$ ), which alone caused a decrease in $P_{\mathrm{o}}$ (Figure $4 \mathrm{~b}, \mathrm{~d}, \mathrm{f}-\mathrm{h}$, Table $\mathrm{S} 1$ ). The $\mathrm{Kcv}_{\mathrm{NTS}}$ G77S F78A mutant had the same high open probability as $\mathrm{Kcv}_{\mathrm{NTS}}$ and the dwell time histogram showed no long closed times (Figure $5 \mathrm{~d}, \mathrm{f}-\mathrm{h})$.

To understand the nature of the gate, i.e., whether the aromatic rings form a barrier by $\pi: \pi$ interactions or whether the side chains are only steric hindrances we replaced F78 in $\mathrm{Kcv}_{S}$ with either Leu or Tyr. An analysis of mutant channel activity showed that the substitution of F78 with Leu-a large, nonaromatic and hydrophobic amino acid-caused a $P_{\mathrm{o}}$ value, which was significantly lower than that in the F78A mutant and even lower than in the $\mathrm{Kcv}_{S}$ wt channel. By analyzing the single channel traces we detected the long lasting closed state, which

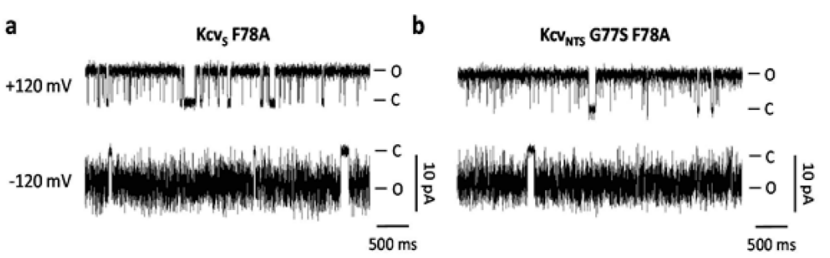

c
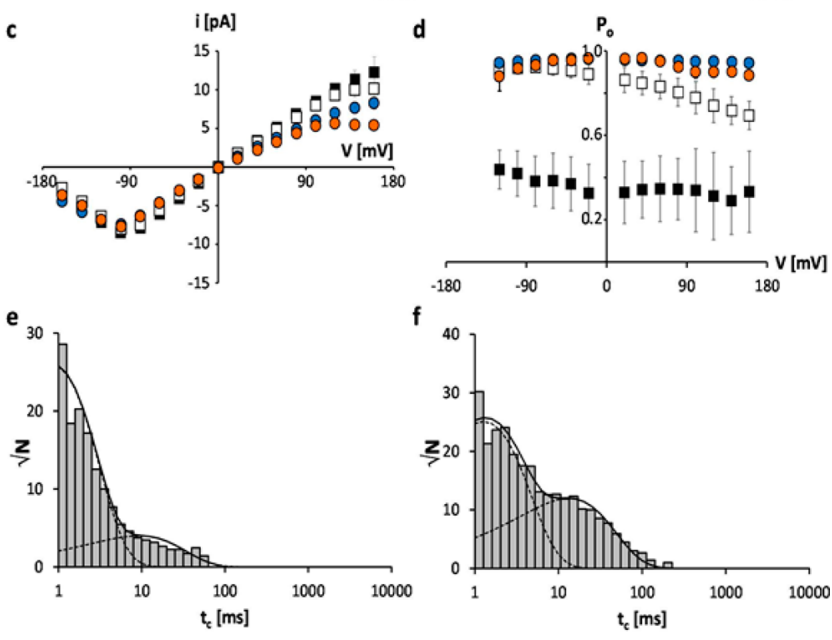

g
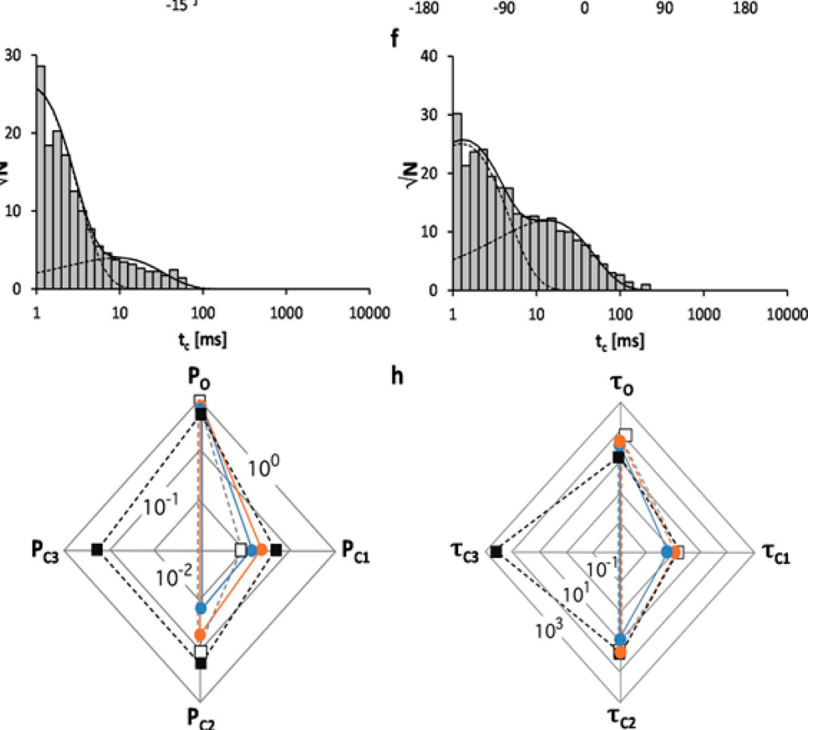

Figure 5. The aromatic AA F78 functions in combination with the upstream AA as a gate for the long closed time. Characteristic single channel fluctuations of mutant $\mathrm{Kcv}_{\mathrm{S}} \mathrm{F} 78 \mathrm{~A}$ (a) and $\mathrm{Kcv}_{\mathrm{NTS}}$ G77S F78A (b) at $\pm 120 \mathrm{mV}$ in planar lipid bilayers. (c) Mean single channel $i / V$ relations ( \pm sd) of $\mathrm{Kcv}_{\mathrm{NTS}}$ (open squares), $\mathrm{Kcv}_{\mathrm{S}}$ (filled squares), $\mathrm{Kcv}_{\mathrm{S}}$ F78A (orange circles, $n=4$ ) and $\mathrm{Kcv}_{\mathrm{NTS}}$ G77S F78A (blue circles, $n=$ 7). (d) Mean open probabilities ( \pm sd) of wt channels and mutants $(n$ $=4$ and $n=7$ for $\mathrm{Kcv}_{\mathrm{S}}$ F78A and $\mathrm{Kcv}_{\mathrm{NTS}}$ G77S F78A, respectively). Exemplary closed dwell times at $+120 \mathrm{mV}$ for $\mathrm{Kcv}_{\mathrm{S}}$ F78A (e) and $\mathrm{Kcv}_{\mathrm{NTS}}$ G77S F78A (f). The data in e and $\mathrm{f}$ can now be fitted with two exponentials. Radar plots for probabilities (P) of the wt channels and mutants for occupying the open state $(\mathrm{O})$ and the closed states $(\mathrm{C} 1-$ C3) (g) and for mean lifetimes (in ms) of the open state $\left(\tau_{\mathrm{o}}\right)$ and of the three closed states $\left(\tau_{c 1}-\tau_{c 3}\right)(\mathrm{h})$. The mean lifetimes were calculated from three independent $5 \mathrm{~min}$ recordings. The symbols in $\mathrm{d}$, $\mathrm{g}$ and $\mathrm{h}$ correspond to those in $\mathrm{c}$.

was eliminated in the F78A mutant. The lower $P_{\mathrm{o}}$ of $\mathrm{Kcv}_{\mathrm{S}} \mathrm{F} 78 \mathrm{~L}$ compared to that of $\mathrm{Kcv}_{\mathrm{S}}$ was the result of a higher probability of occupancy and a longer mean lifetime of the third, long lasting closed state (Figure S4, Table S1). This closed state must be caused by the concerted action of Leu with the upstream Ser because a F78L substitution alone in $\mathrm{Kcv}_{\mathrm{NTS}}$ had no effect on gating (Table S1). F78 in $\mathrm{Kcv}_{\mathrm{S}}$ was also substituted with the polar aromatic Tyr. This caused a significant increase in $P_{\mathrm{o}}$ (Figure S4, Table S1). The results of these experiments establish that F78 is a gate, which is responsible for the long closed events in $\mathrm{Kcv}_{\mathrm{S}}$. It obstructs the flow of ions by creating a hydrophobic barrier in the cavity of the channel. The dynamics of this gate are apparently determined by the adjacent AAs Gly in $\mathrm{Kcv}_{\mathrm{NTS}}$ and Ser in $\mathrm{Kcv}_{S}$. It was previously proposed in other 
channels that the flexible AA Gly could create a hinge in the inner TMD of Kir channels and that this hinge might be essential for gating. ${ }^{10,11}$ In analogy to this model it may be possible that a flexible G77 favors the removal of F78 from the ion pathway while the small Ser does not. To test the relevance of a potential Gly hinge for gating in $\mathrm{Kcv}_{\mathrm{NTS}}$ and $\mathrm{Kcv}_{\mathrm{S}}$ we mutated it into several other small AAs namely Ala, Asn, Ser, Pro and Thr. However, the results of these experiments do not support the hypothesis of a Gly hinge; they show that G77 in $\mathrm{Kcv}_{\text {NTS }}$ can be replaced by other AAs like Ala, which provide no flexibility in an $\alpha$-helix, while still preserving the high open probability (Figure $6 \mathrm{a}, \mathrm{b}$ ). The results of these experiments

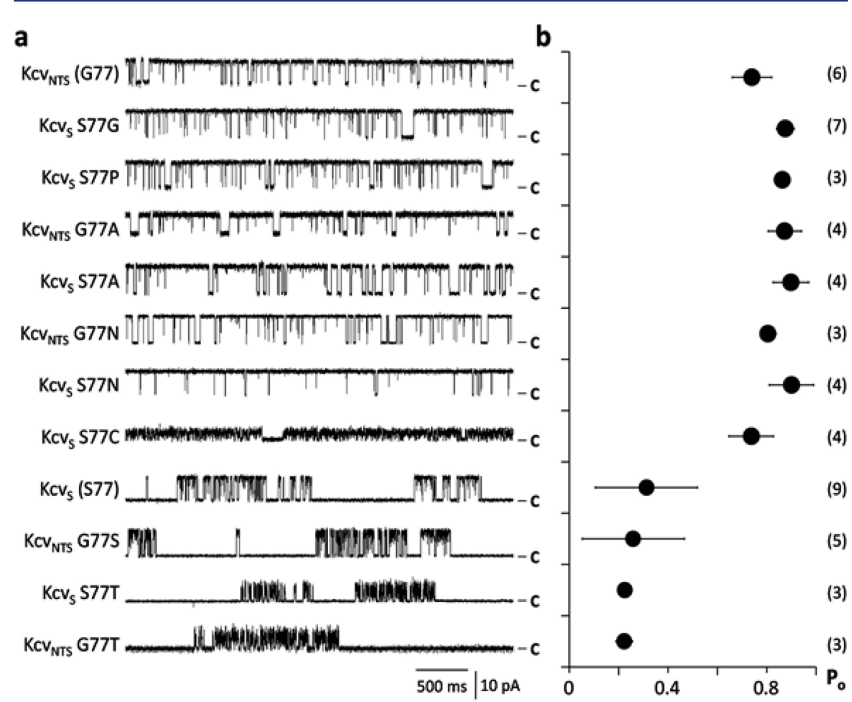

Figure 6. The AA S77 is responsible for the gate with the long closed time. (a) Characteristic single channel fluctuations at $+120 \mathrm{mV}$ of $\mathrm{Kcv}_{\mathrm{S}}$ and $\mathrm{Kcv}_{\mathrm{NTS}}$ and mutants in which the position 77 in both channels was exchanged with an AA with a different flavor. (b) Mean open probabilities $( \pm s d)$ of wt channels and mutants. The number of independent measurements is shown in brackets. Data in b correspond to the constructs on the left in a. Only AAs Ser and Thr in position 77 generate a low open probability with a long lasting closed time.

suggest that Gly is not essential for the high open probability in $\mathrm{KCv}_{\mathrm{NTS}}$ but that Ser is important for the low open probability in $\mathrm{Kcv}_{\mathrm{S}}$. To test this hypothesis we replaced $\mathrm{S} 77$ in $\mathrm{Kcv}_{\mathrm{S}}$ by a number of alternative AAs and measured the function of the mutant channels. The data in Figure 6a,b show that S77 can be replaced in $\mathrm{Kcv}_{\mathrm{S}}$ by different AAs and that these changes result in an increase in open probability. The only replacement of S77, which conserves the low open probability of $\mathrm{Kcv}_{\mathrm{S}}$, is S77T (Figure 6a,b). In agreement, only G77S and G77T in $\mathrm{Kcv}_{\mathrm{NTS}}$ caused a low, $\mathrm{Kcv}_{\mathrm{S}}$-like open probability. These experimental results refute the hypothesis that a Gly mediated hinge plays a crucial role in gating. Instead the data support a gating mechanism, which depends on the $\mathrm{OH}$ group of either Ser or Thr.

A scrutiny of the $i / V$ relations of all the mutants indicated that most AA exchanges have either no or only minor effects on the unitary conductance of the channels (Figure 3c, 4c, 5c, S2S4). In other cases, like in the $\mathrm{Kcv}_{\mathrm{S}}$ mutants, in which F78 was replaced by other AAs, the mutation lowered the apparent unitary conductance of the channel (Figure 5a,c). Since there was no apparent correlation between a mutation on gating and on conductance, we concluded that both processes were independent. The orientation of the F78 side chain in the pathway is apparently not effected by the current through the open channel and vice versa.

Since Ser has no apparent interactive partner within TMD1 (Figure 1) we conclude that the relevant gating entities must be located solely within TMD2. This is consistent with the fact that $\mathrm{Kcv}_{\text {ATCV-1 }}$ also has a high open probability ${ }^{9}$ in spite of some sequence variability with $\mathrm{Kcv}_{\mathrm{NTS}}$ in TMD1 (Figure 1). Potential interacting partners of S77 in TMD2 could be the side chains of S76 or T79. If one of these AAs were involved in the formation of a hydrogen bond with S77, we would expect that substitution with Ala in $\mathrm{Kcv}_{\mathrm{S}}$ would lead to a significant increase in $P_{\mathrm{o}}$ and the disappearance of the long closed events. However, the functional tests showed that both mutants, $\mathrm{Kcv}_{\mathrm{S}} \mathrm{S} 76 \mathrm{~A}$ and $\mathrm{Kcv}_{\mathrm{S}}$ T79A, still exhibited the typical gating of the wt channel (Figure S3). Therefore, S76 and T79 are not part of the gating mechanism. What remains as an explanation for the gating mechanism, in which S77 plays the crucial role, are interactions of the S77 side chain with the peptide backbone. In this context, it is interesting to note that Ser and Thr were found as important structural AAs in $\alpha$-helixes. ${ }^{12,13}$ They can form $\mathrm{H}$ bonds with a carbonyl oxygen in the preceding helix turn and such an intrahelical interaction can generate a kink in the $\alpha$ helix. We reasoned that such a transient Ser interaction in the TMD2 of $\mathrm{Kcv}_{\mathrm{S}}$ could generate a kink in TMD2 in a stochastic manner and that this structural modulation could affect the positioning of F78 in the ion pathway. This hypothesis is consistent with the experimental data. We found that S77 can be functionally replaced in $\mathrm{Kcv}_{\mathrm{S}}$ by Thr but not by Cys (Figure 6a). While Ser and Thr are able to form an intrahelical H-bond, Cys cannot reach the required side chain conformation because of the steric hindrance between the thiol group and the carbonyl oxygen of the AA three positions upstream inside the $\alpha$-helix. ${ }^{14}$

Molecular Dynamics Simulations Disclose Intrahelical Hydrogen Bond. To quantify the structural and dynamical implications of differing sequences between $\mathrm{Kcv}_{\mathrm{S}}$ and $\mathrm{Kcv}_{\mathrm{NTS}}$ on the putative gate in the absence of experimental structural information, we developed a computational model of the two variants. They were examined by molecular dynamics (MD) simulations to determine the angle $\varphi$ between normal vectors placed on the centers of the F78 phenyl rings along with the respective distance $d$ between phenyl centers (see Figure S5). Distributions of these coordinate pairs were averaged over neighboring and opposite monomers for both channel variants, as shown in Figure $7 \mathrm{a} . \mathrm{Kcv}_{\mathrm{S}}$ shows a densely populated area of opposite monomer residues with an angle less than $20^{\circ}$ and around 3-8 $\AA$ distance, and another area with less population at around $50-60^{\circ}$ and more than $18 \AA$ distance. The area with the smaller angle/distance pairs can be identified with $\pi$-stack geometries. $\mathrm{Kcv}_{\mathrm{NTS}}$ has similar areas of likely monomer distances at 3-8 and about $20 \AA$, but with on average larger angles between the phenyl residues. The angles of the area at around 3-8 $\AA$ distance fall in the range between $20^{\circ}$ and $40^{\circ}$, implying much weaker $\pi: \pi$ interactions. The angle of the area around $20 \AA$ is also much larger with angles between $60^{\circ}$ and $100^{\circ}$. Angle/distance pairs between phenyl rings in neighboring monomers of $\mathrm{Kcv}_{\mathrm{S}}$ occur with high probability at 8-13 $\AA$ and $20^{\circ}-40^{\circ}$, whereas in the $\mathrm{Kcv}_{\mathrm{NTS}}$ channel a substantially less focused area is found covering a wider angle range. In summary, the results indicate more pronounced structural rigidity for $\mathrm{Kcv}_{\mathrm{S}}$ over $\mathrm{Kcv}_{\mathrm{NTS}}$, combined with a slightly larger propensity of the $\mathrm{Kcv}_{S}$ variant to form $\pi$-stack pairs between opposite monomers that could potentially block the translocation 

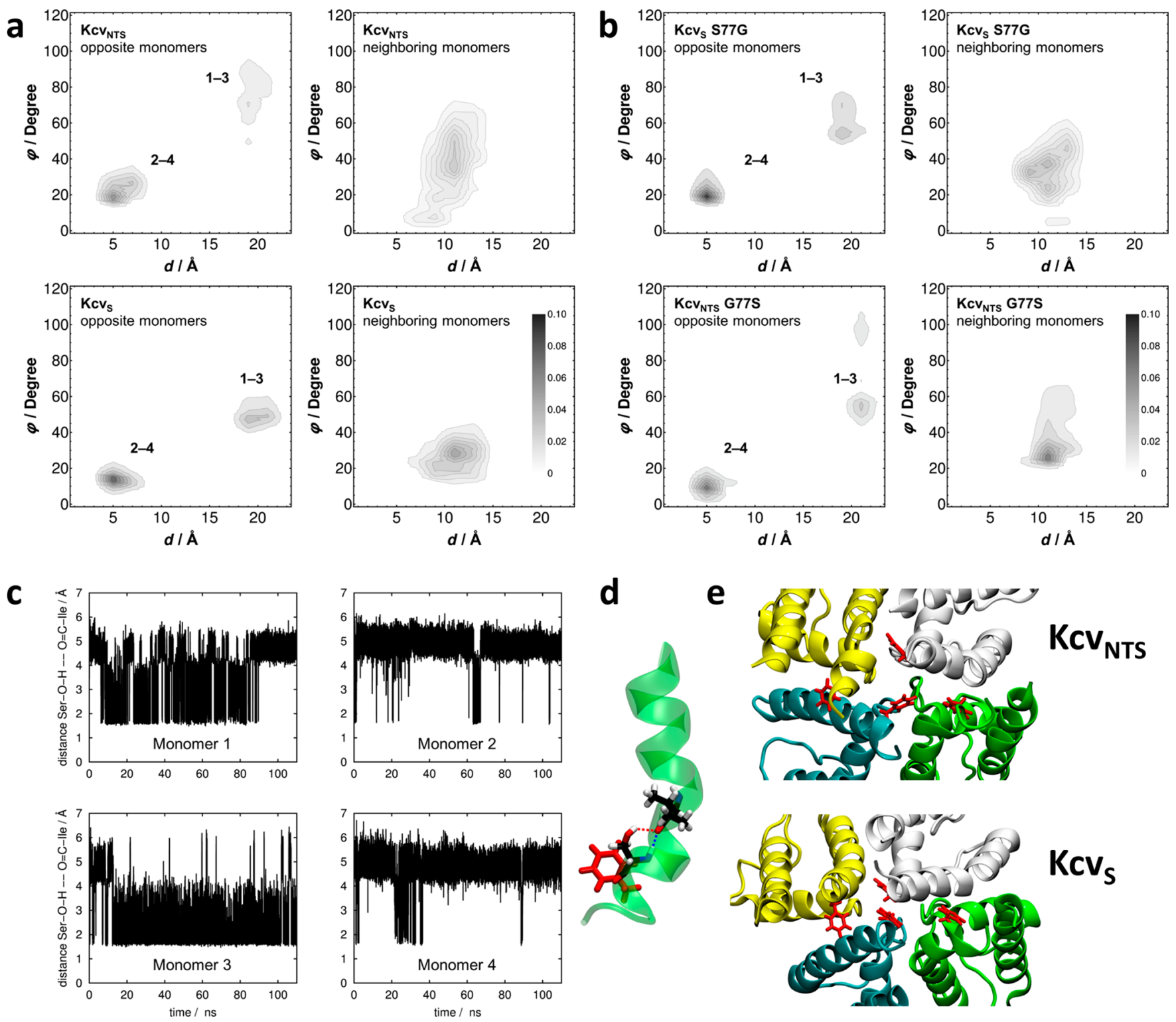

Figure 7. Dynamics of TMD2 in $\mathrm{Kcv}_{\mathrm{S}} / \mathrm{Kcv}_{\mathrm{NTS}}$ and mutants. (a) Distribution of distance-angle pairs characterizing $\pi$-stack geometries in Kcv ${ }_{\mathrm{NTS}}$ (top row) and $\mathrm{Kcv}_{S}$ (bottom row) averaged over all F78 pairs in opposite (left column) and neighboring (right column) monomers. The geometric criteria are shown Figure S5. Numbers in the left panel denote different monomers. (b) Analogous data for $\mathrm{Kcv}_{\mathrm{S}}$ S77G and Kcv $\mathrm{NTS}_{\mathrm{NTS}} \mathrm{G} 77 \mathrm{~S}$ mutants, demonstrating the transfer of $\pi$-stack characteristics upon mutating the key residues. (c) Time series of the distances between the carbonyl oxygen of I73 and the hydroxyl hydrogen of S77 for all four monomers. (d) Schematic representation of a hydrogen bond formed between the amide oxygen of I73 and the hydroxyl hydrogen of S77 within monomer 3 of $\mathrm{Kcv}_{\mathrm{S}}$ supplemented by orientation of F78 (snapshot taken at $80 \mathrm{ns).} \mathrm{(e)} \mathrm{Snapshots} \mathrm{of}$ F78 (red) in tetramer of $\mathrm{Kcv}_{\mathrm{NTS}}$ (top) and $\mathrm{Kcv}_{\mathrm{S}}$ (bottom) representing a wider and a narrow translocation pathway corresponding to statistics shown in a.

pathway. This structural and dynamical observation could be correlated with the functional differences between both variants expressed by the larger open probability of $\mathrm{Kcv}_{\mathrm{NTS}}$.

$\mathrm{MD}$ simulations were also used to test the hypothesis that the functional gate hinges upon possible hydrogen bond interactions between S77 and the helix backbone at the I73 position in $\mathrm{Kcv}_{\mathrm{S}}$ (Figure $7 \mathrm{~d}$ ). We therefore calculated the distances between the S77 hydroxyl hydrogens and I73 backbone amide oxygens as a measure for H-bonding patterns for all monomers, as depicted in Figure $7 \mathrm{c}$. Two distinct states were identified, one of which with a smaller distance at about 2 $\AA$ corresponded to an H-bond. Remarkably, oppositely placed and neighboring residues behaved differently, at least on the observed simulation time scale. Monomers 1 and 3 (opposite) show predominantly the hydrogen bond, whereas in the other pair of opposite monomers (2 and 4 ), it occurs much less frequently. This inherent asymmetry is likely inherited from the KirBac1.1 template structure that can be interpreted as a "dimer of dimers" pairwise asymmetric state, which also explains the $1-3 / 2-4$ difference found for the $\pi$-stack statistics.

Deeper analysis of $\pi$-stack statistics for separate monomer units (Figure 7c) revealed that monomers 2 and 4 (broken $\mathrm{H}$ bonds) were more likely to form $\pi$-stack geometries (not shown). In other words, the formation of hydrogen bonds within a monomer is correlated with the phenyl ring motion by bending them away from the translocation pathway, allowing oppositely placed phenyl groups to interact more strongly, 
thereby blocking ion translocation as a signature of a closed channel.

In order to test the hypothesis that our geometric $\pi$-stack definitions represent valid descriptors that correlate with functional states, we designed two computational control experiments. Following the experimental strategy, we created $\mathrm{Kcv}_{\mathrm{S}}$ S77G and $\mathrm{Kcv}_{\mathrm{NTS}}$ G77S mutants based on the respective last frames of the $\mathrm{Kcv}_{S}$ and $\mathrm{Kcv}_{\mathrm{NTS}}$ runs. This inverts the experimental behavior, and-as hoped for-we could also reproduce the angle/distance distributions of $\mathrm{Kcv}_{\mathrm{S}}$ by $\mathrm{Kcv}_{\mathrm{NTS}}$ G77S and those of $\mathrm{Kcv}_{\mathrm{NTS}}$ by $\mathrm{Kcv}_{\mathrm{S}}$ S77G (see Figure $7 \mathrm{~b}$ ). Hence, we conclude that our $\pi$-stack descriptor (angle/distance pairs) indeed correlates with open/closed state propensities even in the absence of a functionally open, conductive simulation system.

Absence or Presence of Ser77 Alters Orientation of CTerminal Part of TMD2. The experimental and computational data agree with the view that the gating differences between the two channels are determined by the presence or absence of a kink in TMD2. The modeling data further suggest that this could result in an altered orientation of the TMD2 downstream of F78. In order to test the hypothesis that a helix kink has an effect on the orientation of the last part of TMD2 we experimentally created mutants in which the AA W82 in $\mathrm{Kcv}_{\mathrm{NTS}}$ and $\mathrm{Kcv}_{\mathrm{S}}$ was replaced with a Cys. We reasoned that a different orientation of the TMD helixes in the mutant channels should affect the propensity of forming sulfhydryl bridges between the terminal Cys. The functional data of the mutant channels strongly supports this hypothesis. The exemplary current traces of the $\mathrm{Kcv}_{\mathrm{S}}$ W82C mutant show that this channel has a reduced unitary conductance with different conductance levels (Figure 8a). The low unitary conductance was partially

a
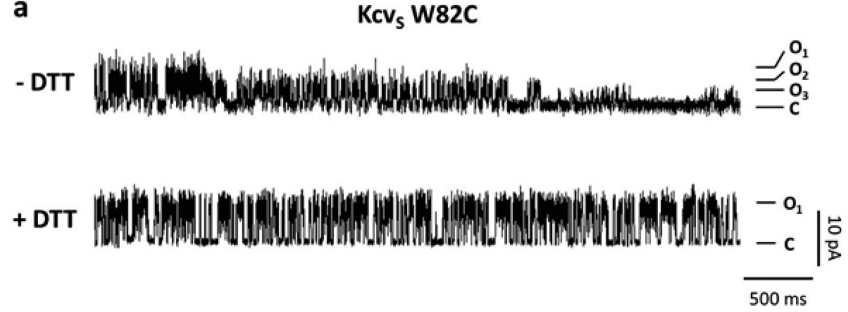

b

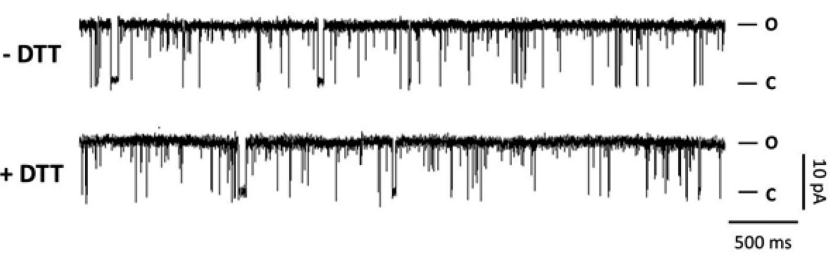

Figure 8. The two channels $\mathrm{Kcv}_{\mathrm{S}}$ and $\mathrm{Kcv}_{\mathrm{NTS}}$ have a different orientation of the $\mathrm{C}$-terminus. Characteristic single channel fluctuations at $+120 \mathrm{mV}$ of $\mathrm{Kcv}_{\mathrm{S}} \mathrm{W} 82 \mathrm{C}(\mathrm{a})$ and $\mathrm{Kcv}_{\mathrm{NTS}} \mathrm{W} 82 \mathrm{C}$ (b) in absence $(-\mathrm{DTT})$ and presence of $5 \mathrm{mM}$ DTT (+DTT) in bath solution. The prevailing open $(\mathrm{O})$ and closed $(\mathrm{C})$ levels are indicated along the traces.

rescued by adding DTT. This finding suggests that the terminal Cys forms sulfhydryl bridges, which lowers the conductance at the cytosolic exit of this mutant channel. The $\mathrm{Kcv}_{\mathrm{NTS}} \mathrm{W} 82 \mathrm{C}$ mutant on the other hand functions like the wt $\mathrm{Kcv}_{\mathrm{NTS}}$ channel and does not respond to DTT (Figure $8 \mathrm{~b}$ ). The terminal Cys must be oriented in the $\mathrm{Kcv}_{\mathrm{NTS}} \mathrm{W} 82 \mathrm{C}$ mutant in such a way that it is unable to form sulfhydryl bridges.

\section{CONCLUSION}

Ion channels typically exhibit open and closed states with different lifetimes in single channel recordings. It is generally believed that each of these closed dwell times reflects the dynamics of a distinct gate. In the present study we causally linked one long-lived closed state in the $\mathrm{Kcv}_{S}$ channel to a simple electrostatic interaction in the channel protein. The presence of a Ser (or Thr) in the inner TMD of the $\mathrm{Kcv}_{S}$ channel promotes formation of an intrahelical $\mathrm{H}$-bond and a consequent kink in this helix. The kink, which according to the data in Figure 8 also generates a twist in the lower part of the helix, has by itself no impact on gating. The channel only acquires a long-lived closed state when the AA downstream of the critical Ser has an aromatic or a long hydrophobic side chain. The computational data suggest the following scenario: the formation of hydrogen bonds within a transmembrane domain moves the phenyl ring of this domain out of the cavity giving room for a movement of the adjacent phenyl groups toward the pore center. These structural changes in the ns time window trigger a long-lived conformation, which closes the ion pathway. Hence the closing of the pore reflects a close interplay between all four monomers.

A similar gate, in which hydrophobic aromatic or aliphatic side chains serve as an obstruction of ion flow, has previously been proposed for other ion channels including complex $\mathrm{K}^{+}$ channels. ${ }^{15}$ From the crystal structure of KirBac channels it was deduced that the aromatic side chain of a Phe within the intracellular half of the inner helix could project into the channel pore and close it. Opening of the channels was presumably promoted by an upstream Gly kink in the inner helix with a simultaneous retraction of the aromatic ring from the ion pathway. ${ }^{16-19}$ Since many Kir channels have a hydrophobic aromatic Phe or aliphatic Leu at this position, ${ }^{20}$ it was proposed that they may constitute a general gate in the Kir family. In the case of Kir6.2 and Kir1.1 it was already experimentally confirmed that the respective Phe and Leu are involved in a $\mathrm{pH}$ sensitive gating of these channels. ${ }^{20,21}$

The present data further underscore the relevance of Phe and Leu in gating. But different from Kir channels their function as a gate is not connected to a flexible Gly hinge. Both the $\mathrm{Kcv}_{S}$ and the $\mathrm{Kcv}_{\mathrm{NTS}}$ channels have a Phe in the same position in the inner helix. This Phe serves as a gate only in combination with an adjacent Ser. Placing a Gly in this position, which occurs in many Kcv channels, does not affect gating. The Phe side chain only becomes relevant as a gate in combination with an upstream AA like Ser or Thr, which is able to form an intrahelical H-bond. In this scenario Phe serves as the door and Ser as the hinge of the door in the $\mathrm{Kcv}_{\mathrm{S}}$ channel.

The detailed analysis of single channel data shows that the Ser/Phe gate at the entry to the $\mathrm{Kcv}_{\mathrm{s}}$ channel functions autonomously. The presence or absence of this gate has no appreciable impact on the two remaining closed dwell times. This is different from other studies in which channel gating was examined in the context of an individual gate. In the case of the KcsA channel it was reported that any modification of the filter gate or of the $\mathrm{pH}$ sensitive gate always resulted in a complex modulation of several open and/or closed dwell times. ${ }^{2,3}$ In Kir6.2 channels, removal of the critical Phe at the inner gate affects the stability of both open and closed states. ${ }^{20}$ This is consistent with the idea that the dynamics of the Ser/Phe gate 
in $\mathrm{Kcv}_{\mathrm{S}}$ is governed only by a single conformational alteration. The filter gate or the $\mathrm{pH}$ sensitive gate in KcsA in contrast may involve a network of electrostatic interactions, which include more than one defined conformational state.

While the MD simulation data provided a detailed insight into the structural components of the gate they do not completely describe the dynamics of the gating process due to the simulation time restriction. MD provides structural/ dynamical correlates with function, not the complete microscopic picture. However, the MD simulations confirm that the intrahelical $\mathrm{H}$-bond promotes a positioning of the Phe in the ionic pathway; this can generate $\pi: \pi$ stacking interactions between aromatic rings from different monomers. Computational mutation tests confirmed the relevance of $\pi: \pi$ stacking for understanding the gating transition, in line with the experimental finding that switching $S$ and $G$ at position 77 inverts the open/closed propensities of $\mathrm{Kcv}_{\mathrm{NTS}}$ and $\mathrm{Kcv}_{S}$. The results of the simulations suggest that the $\alpha$-helix can dynamically fluctuate between a straight and bended conformation, correlating with switching H-bond patterns. A similar observation was reported from long MD simulations in which the backbone structure of an $\alpha$-helix in the pore domain of a voltage gated $\mathrm{Na}^{+}$channel undergoes dynamic deformation in response to the making and breaking of intrahelical H-bonds. ${ }^{22}$ All of these events occur in the time window of ns (Figure $7 \mathrm{c}$ ) or $\mu \mathrm{s}^{22}$ while the lifetime of the closed state is in the range of hundreds of ms. Hence it is still not possible to directly correlate the lifetime of the closed state with the lifetime of an interaction or a conformational state of the channel protein. We can only exclude the possibility that the respective long-lived close state reflects the short lifetime of $\pi: \pi$ stacking between the aromatic rings of neighboring Phe; notably a similar long close time is also observed when the Phe residues are replaced by Leu.

The importance of intrahelical H-bonds and their potential role in channel gating have not been reported previously. However, we predict that similar mechanisms, which are relevant in the simple Kcv channels, could be important in the gating of complex eukaryotic channels. Extensive structural studies have shown that either Ser or Thr induce either alone or in combination with Pro distinct distortions in transmembrane domains of many proteins including ion channels. ${ }^{23-25}$ Some isolated data already suggest that such Ser or Thr mediated intrahelical H-bonds have an effect on protein function. ${ }^{24,26}$ Notably, pairs of Ser or Thr together with aromatic or large hydrophobic AAs are also frequently present in the inner TMDs of $\mathrm{K}^{+}$channels. The BK channel for example has a SFF338-340 motive at the cytosolic end of the pore lining TMD in which Ser and both Phes are involved in channel gating. $^{27,28}$

\section{EXPERIMENTAL SECTION}

Cloning, Mutagenesis, Protein Expression and Purification. The two viruses encoding the $\mathrm{Kcv}_{\mathrm{NTS}}$ and $\mathrm{Kcv}_{S}$ channels were originally isolated from alkaline lakes in western Nebraska. For cellfree protein expression the coding sequences of $\mathrm{Kcv}_{\mathrm{NTS}}$ and $\mathrm{Kcv}_{\mathrm{S}}$ as well as their chimeras $\left(\mathrm{Kcv}_{\mathrm{NTS} / \mathrm{S}}, \mathrm{Kcv}_{\mathrm{S} / \mathrm{NTS}}\right)$ were cloned into the pEXP5-CT/TOPO-vector with the pEXP5-CT/TOPO TA Expression Kit (Invitrogen). To express the channel proteins in their native form, a stop-codon was inserted directly upstream of the coding sequence of a 6xHis-tag. The sequences of $\mathrm{Kcv}_{\mathrm{NTS} / \mathrm{S}}$ and $\mathrm{Kcv}_{\mathrm{S} / \mathrm{NTS}}$ were generated by fusion-PCR. ${ }^{29}$ All mutations were introduced by site-directed mutagenesis using a protocol based on the method described in. ${ }^{30}$ The coding regions of all constructs were sequenced. In vitro expression of the channel proteins were performed with the MembraneMax HN Protein Expression Kit (Invitrogen) following the manufacturer's instructions. The in vitro expression takes place in the presence of nanolipoproteins (NLPs) ${ }^{31}$ fused with multiple His-tags. This allows the purification of the native channel proteins by metal chelate affinity chromatography. For purification the crude reaction mixture was loaded on a $0.2 \mathrm{~mL}$ HisPur Ni-NTA spin column (Thermo Scientific). All steps were performed according to the manufacturer's instructions, with the exception of the elution step. To elute the NLP/channel conjugates the spin column was washed three times with two resin-bed volumes of $250 \mathrm{mM}$ imidazole.

Planar Lipid Bilayer Experiments. All planar lipid bilayer experiments were performed at room temperature $\left(20-25^{\circ} \mathrm{C}\right)$ with a conventional bilayer setup (IonoVation, Osnabrück Germany). The preparation of the recording chambers was done as described earlier. ${ }^{32}$ Both chambers were connected with $\mathrm{Ag} / \mathrm{AgCl}$ electrodes to the headstage of a patch-clamp amplifier (L/M-EPC-7, List-Medical, Darmstadt). Membrane potentials were referred to the cis compartment. Current traces were filtered at $1 \mathrm{kHz}$ with a 4-pole Bessel filter and digitized with a sampling frequency of $5 \mathrm{kHz}$ by an $\mathrm{A} / \mathrm{D}$-converter (LIH 1600, HEKA Elektronik, Lambrecht, Germany). 1,2-Diphytanoyl-sn-glycero-3-phosphocholine (DPhPC, Avanti Polar Lipids, Alabaster, AL, USA) bilayers were formed by the Pseudo painting/ air bubble technique ${ }^{33}$ in symmetrical $100 \mathrm{mM} \mathrm{KCl}$ solution ( $\mathrm{pH} \mathrm{7}$, buffered with $10 \mathrm{mM}$ HEPES). For reconstitution of channel proteins a small amount $(1-3 \mu \mathrm{L})$ of the purified NLP/channel-conjugates diluted in $250 \mathrm{mM}$ imidazole solution was added directly below the bilayer in the trans compartment with a bent Hamilton syringe. After successful incorporation of a single channel in the DPhPC bilayer, constant voltages were applied for 1 to $5 \mathrm{~min}$. Voltage was changed in steps of $20 \mathrm{mV}$ between $+160 \mathrm{mV}$ and $-160 \mathrm{mV}$.

Data Analysis. Single-channel current traces were recorded with Patchmaster (HEKA) and analyzed with the custom-made program Kielpatch (http://www.zbm.uni-kiel.de/aghansen/software.html). Single channel amplitudes were measured visually. For determination of open probabilities an automated Hinkley jump detector ${ }^{34}$ was used. Dwell time histograms were fitted with sums of 1 to 3 exponential functions. The number of missed closed times, which were not resolved because of a limited temporal resolution of the recording setup, were estimated from the obtained fitting parameters. The calculated numbers of missed closed-events were used to correct the mean lifetimes of the open state. For this we assumed (i) that the missed closed events are randomly distributed over the open events, and (ii) that the missed closed events have a negligible effect on the total time of the channel in the open state.

For calculating the probabilities of occupancy, we assumed a simple Markov model in which all closed states were directly coupled to the open state with no unobservable closed-closed transitions. If additional information on the state transitions become available in the future, which require a modification of this model topology, algorithms are available to transform equivalent models into each other. $^{35}$

Homology Modeling. The closed KirBacl.1 structure (PDB code: 1 P7 $\mathrm{B}^{16}$ ) was chosen as a template for initial homology modeling of the $\mathrm{Kcv}_{\mathrm{S}}$ and $\mathrm{Kcv}_{\mathrm{NTS}}$ geometries, following closely the methodology for developing $\mathrm{Kcv}_{\mathrm{PBCV}-1}{ }^{4}$ and $\mathrm{Kcv}_{\mathrm{ATCV}-1}{ }^{31}$ models. The template tetramer was constructed from the KirBacl.1 monomer by applying the provided symmetry operations using VMD 1.9.1. ${ }^{36}$ Deletion of the cytosolic domain resulted in a truncated KirBacl.1 tertiary structure sharing the same total number of 82 residues. Sequence alignments using CLUSTAL (version 2.1) ) $^{37}$ revealed large gaps, which would lead to helix breaks. These were circumvented by restraining residues $10-$ 15 and $75-82$ to an $\alpha$-helical structure during model preparation using Papwoth (version 9.10) ${ }^{38,39}$ with default settings for optimization cycles.

The energetically most favored model out of ten was identified by its DOPE score and further processed. Hydrogen atoms were added by CHARMM's HBUILD tool, ${ }^{40}$ keeping all titratable residues in their standard protonation state at neutral $\mathrm{pH}$; C-terminal residues remained deprotonated and the $\mathrm{N}$-termini residues were protonated; 
His residues were protonated at their $\delta$-nitrogen. The resulting models were minimized in the presence of two ions (selectivity filter binding sites S2 and S4) and two water molecules (sites S1 and S3) introduced at the filter positions by adapting the available information from the KirBac1.1 structure. PROCHECK was utilized in its online version (http://www.ebi.ac.uk/pdbsum/ $)^{41}$ to assess the model quality, ignoring hydrogen atoms.

Molecular Dynamics Simulations. Again following the methodology for simulating the $\mathrm{Kcv}_{\mathrm{ATCV}-1}$ wild type system ${ }^{32}$ the KirBac1.1based homology models of $\mathrm{Kcv}_{S}$ and $\mathrm{Kcv}_{\mathrm{NTS}}$ were inserted into a preequilibrated DMPC bilayer membrane utilizing the CHARMM-GUI tools ${ }^{42}$ by deletion of lipid molecules colliding with any protein residues within a sharp radius of $0.5 \AA$ of the protein, resulting in a membrane comprising 192 lipid species in total with 90 molecules in the upper and 102 in the lower layer induced by the conic protein shape. 16726 water molecules (TIP3P model) ${ }^{43}$ were added, removing water molecules inside the membrane. By random exchange with 60 water molecules $31 \mathrm{Cl}^{-}$and $29 \mathrm{~K}^{+}$ions were introduced into the bulk solution creating a concentration of approximately $100 \mathrm{mM} \mathrm{KCl}$. With the two $\mathrm{K}^{+}$ions already located inside the selectivity filter electroneutrality of the entire system was achieved. The initial system dimensions were ca. $90 \AA \times 90 \AA \times 115 \AA$ along $x, y$ and $z$ dimensions, with the latter representing the channel axis. Periodic boundary conditions were employed by treating electrostatics with the particle mesh Ewald algorithm ${ }^{44}$ using a spacing of $0.1 \AA$ between grid points and a real-space short-range cutoff of $12 \AA$. The temperature was set to $300 \mathrm{~K}$ for production runs, controlled by a Langevin thermostat with a damping coefficient of $1 \mathrm{ps}^{-1}, 45$ and a pressure of $1 \mathrm{~atm}$ was applied by a Langevin-piston Nose-Hoover barostat. ${ }^{46}$ The CHARMM22* force field for proteins and CHARMM27 for lipids were applied throughout the simulations ${ }^{47,48}$ with ion parameters as used earlier. ${ }^{4,32}$ NAMD (version 2.9) was used for performing simulations. ${ }^{49}$ After minimization and equilibration with gradually removing restraints over $12.7 \mathrm{~ns}$, production runs were performed over $110 \mathrm{~ns}$ for each variant, sampled at each ps for further evaluation. A snapshot of the $\mathrm{Kcv}_{S}$ structure is shown in Figure 1A. The quality of the MD simulations is demonstrated in Supplementary Figure S6, where the root-mean-square displacements (RMSD) indicate long-time stability. Point mutations to create $\mathrm{Kcv}_{\mathrm{NTS}} \mathrm{G} 77 \mathrm{~S}$ and $\mathrm{Kcv}_{\mathrm{S}}$ S77G were introduced by the $\mathrm{VMD}^{35}$ "Mutator" plugin on the last frame of the original $\mathrm{MD}$ runs of the respective wildtypes and further simulated over $80 \mathrm{~ns}$.

\section{ASSOCIATED CONTENT}

\section{S Supporting Information}

The Supporting Information is available free of charge on the ACS Publications website at DOI: 10.1021/jacs.7b01158.

Open and closed dwell times of channel mutants and more details on molecular dynamics simulations (PDF)

\section{AUTHOR INFORMATION}

\section{Corresponding Author}

*thiel@bio.tu-darmstadt.de

\section{ORCID}

Stefan M. Kast: 0000-0001-7346-7064

Gerhard Thiel: 0000-0002-2335-1351

Notes

The authors declare no competing financial interest.

\section{ACKNOWLEDGMENTS}

This research was supported by the Deutsche Forschungsgemeinschaft SCHR1467/1-1 (IS) the European Research Council NoMAGIC grant (AM, GT) the LOEWE initiative iNAPO (GT), and PGR00139 from MAECI (Ministero affari esteri e cooperazione internazionale), CARIPLO grant 20140660 (AM). NSF - EPSCOR Grant EPS-1004094 (JVE) and the COBRE program of the National Center for Research Resources Grant P20-RR15535 (JVE). The IT and Media Center (ITMC) of the TU Dortmund is acknowledged for computational support (SMK).

\section{REFERENCES}

(1) Hille, B. Ion Channels of Excitable Membranes, 3rd ed.; Sinauer Associates Inc.: Sunderland, 2001.

(2) Cordero-Morales, J. F.; Cuello, L. G.; Zhao, Y.; Jogini, V.; Cortes, D.; Roux, B.; Perozo, E. Nat. Struct. Mol. Biol. 2006, 13, 311.

(3) Thompson, A. N.; Posson, D. J.; Rarsa, P. V.; Nimigean, C. M. Proc. Natl. Acad. Sci. U. S. A. 2008, 105, 6900.

(4) Tayefeh, S.; Kloss, T.; Kreim, M.; Gebhardt, M.; Baumeister, D.; Hertel, B.; Richter, C.; Schwalbe, H.; Moroni, A.; Thiel, G.; Kast, S. M. Biophys. J. 2009, 96, 485.

(5) Thiel, G.; Baumeister, D.; Schroeder, I.; Kast, S. M.; Van Etten, J. L.; Moroni, A. Biochim. Biophys. Acta, Biomembr. 2011, 1808, 580.

(6) Abenavoli, A.; DiFrancesco, M.; Schroeder, I.; Epimashko, S.; Gazzarrini, S.; Hansen, U. P.; Thiel, G.; Moroni, A. J. Gen. Physiol. 2009, 134, 869.

(7) Kang, M.; Moroni, A.; Gazzarrini, S.; DiFrancesco, D.; Thiel, G.; Severino, M.; Van Etten, J. L. Proc. Natl. Acad. Sci. U. S. A. 2004, 101, 5318.

(8) Gazzarrini, S.; Kang, M.; Van Etten, J. L.; DiFrancesco, D.; Thiel, G.; Moroni, A. J. Biol. Chem. 2004, 279, 28443.

(9) Gazzarrini, S.; Kang, M.; Abenavoli, A.; Romani, G.; Olivari, C.; Gaslini, D.; Ferrara, G.; Van Etten, J. L.; Kreim, M.; Kast, S. M.; Thiel, G.; Moroni, A. Biochem. J. 2009, 420, 295.

(10) Jiang, Y.; Lee, A.; Chen, J.; Cadene, M.; Chait, B. T.; MacKinnon, R. Nature 2002, 417, 523.

(11) Shrivastava, I. H.; Bahar, I. Biophys. J. 2006, 90, 3929.

(12) Ballesteros, J. A.; Deupi, X.; Olivella, M.; Haaksma, E. E.; Pardo, L. Biophys. J. 2000, 79, 2754.

(13) Hall, S. E.; Roberts, K.; Vaidehi, N. J. Mol. Graphics Modell. 2009, 27, 944.

(14) McGregor, M. J.; Islam, S. A.; Sternberg, M. J. E. J. Mol. Biol. 1987, 198, 295.

(15) Zhou, H. X.; McCammon, J. A. Trends Biochem. Sci. 2009, 35, 179.

(16) Kuo, A.; Gulbis, J. M.; Antcliff, J. F.; Rahman, T.; Lowe, E. D.; Zimmer, J.; Cuthbertson, J.; Ashcroft, F. M.; Ezaki, T.; Doyle, D. A. Science 2003, 300, 1922.

(17) Kuo, A.; Domene, C.; Johnson, L. N.; Doyle, D. A.; VénienBryan, C. Structure 2005, 13, 1463.

(18) Nishida, M.; Cadene, M.; Chait, B.-T.; MacKinnon, R. EMBO J. 2007, 26, 4005.

(19) Clayton, G. M.; Altieri, S.; Heginbotham, L.; Unger, V. M.; Morais-Cabral, J. H. Proc. Natl. Acad. Sci. U. S. A. 2008, 105, 1511.

(20) Rojas, A.; Wu, J.; Wang, R.; Jiang, C. Biochim. Biophys. Acta, Biomembr. 2007, 1768, 39.

(21) Sackin, H.; Nanazashvili, M.; Palmer, L. G.; Krambis, M.; Walters, D. E. Biophys. J. 2005, 88, 2597.

(22) Boiteux, C.; Vorobyov, I.; Allen, T. W. Proc. Natl. Acad. Sci. U. S. A. 2014, 111, 3454.

(23) Deupi, X.; Olivella, M.; Sanz, A.; Dölker, N.; Campillo, M.; Pardo, L. J. Struct. Biol. 2010, 169, 116.

(24) Deupi, X.; Olivella, M.; Govaerts, C.; Ballesteros, J. A.; Campillo, M.; Pardo, L. Biophys. J. 2004, 86, 105.

(25) Perea, M.; Lugtenburg, I.; Mayol, E.; Cordomi, A.; Deupí, X.; Pardo, L. BMC Bioinf. 2015, 16, 26.

(26) Sansuk, K.; Deupi, X.; Torrecillasm, I. R.; Jongejan, A.; Nijmeijer, S.; Bakker, R. A.; Pardo, L.; Leurs, R. Mol. Pharmacol. 2011, 79, 262.

(27) Strutz-Seebohm, N.; Pusch, M.; Wolf, S.; Stoll, R.; Tapken, D.; Derwert, K.; Attali, B.; Seebohm, G. Cell. Physiol. Biochem. 2011, 27, 443.

(28) Panaghie, G.; Purtell, K.; Tai, K. K.; Abbott, G. W. Biophys. J. 2008, 95, 2759. 
(29) Horton, R. M.; Hunt, H. D.; Ho, S. N.; Pullen, J. K.; Pease, L. R. Gene 1989, 77, 61.

(30) Papworth, C.; Bauer, J. C.; Braman, J.; Wright, D. A. Strategies 1996, 9, 3.

(31) Katzen, F. BioTechniques 2008, 45, 190.

(32) Braun, C. J.; Lachnit, C.; Becker, P.; Henkes, L. M.; Arrigoni, C.; Kast, S. M.; Moroni, A.; Thiel, G.; Schroeder, I. Biochim. Biophys. Acta, Biomembr. 2014, 1838, 1096.

(33) Braun, C.; Baer, T.; Moroni, A.; Thiel, G. J. Neurosci. Methods 2014, 233C, 13.

(34) Schultze, R.; Draber, S. J. Membr. Biol. 1993, 132, 41.

(35) Kienker, P. Proc. R. Soc. London, Ser. B 1989, 236, 269.

(36) Humphry, W.; Dalke, A.; Schulten, K. J. J. Mol. Graphics 1996, $14,33$.

(37) Larkin, M. A.; Blackshields, G.; Brown, N. P.; Chenna, R.; McGettigan, P. A.; McWilliam, H.; Valentin, F.; Wallace, I. M.; Wilm, A.; Lopez, R.; Thompson, J. D.; Gibson, T. J.; Higgins, D. G. Bioinformatics 2007, 23, 2947.

(38) Webb, B.; Sali, A. Methods Mol. Biol. 2014, 1137, 1.

(39) Shen, M. Y.; Sali, A. Protein Sci. 2006, 15, 2507.

(40) Brünger, A. T.; Karplus, M. Proteins: Struct., Funct., Genet. 1988, 4, 148.

(41) Laskowski, R. A.; MacArthur, M. W.; Moss, D. S.; Thornton, J. M. J. Appl. Crystallogr. 1993, 26, 283.

(42) Jo, S. J. Comput. Chem. 2008, 29, 1859.

(43) Jorgensen, W. L.; Chandrasekhar, J.; Madura, J. D.; Impey, R. W.; Klein, M. L. J. J. Chem. Phys. 1983, 79, 926.

(44) Darden, T.; York, D.; Pedersen, L. J. Chem. Phys. 1993, 98, 10089.

(45) Kubo, R.; Toda, M.; Hashitsume, N. Statistical Physics II: Non equilibrium Statistical Mechanics, 2nd ed.; Springer: Berlin, Heidelberg, 1991.

(46) Feller, S. E.; Zhang, Y.; Pastor, R. W.; Brooks, B. R. J. Chem. Phys. 1995, 103, 4613.

(47) Buck, M.; Bouguet-Bonnet, S.; Pastor, R. W.; MacKerell, A. D. Biophys. J. 2006, 90, 36.

(48) MacKerell, A. D.; Bashford, D.; Bellott, M.; Dunbrack, R. L.; Evanseck, J. D.; Field, M. J.; Fischer, S.; Gao, J.; Guo, H.; Ha, S.; Joseph-McCarthy, D.; Kuchnir, L.; Kuczera, K.; Lau, F. T.; Mattos, C.; Michnick, S.; Ngo, T.; Nguyen, D. T.; Prodhom, B.; Reiher, W. E.; Roux, B.; Schlenkrich, M.; Smith, J. C.; Stote, R.; Straub, J.; Watanabe, M.; Wiórkiewicz-Kuczera, J.; Yin, D.; Karplus, M. J. Phys. Chem. B 1998, 102, 3586.

(49) Phillips, J. C.; Braun, R. J. Comput. Chem. 2005, 26, 1781. 


\section{Identification of intra-helical bifurcated $\mathrm{H}$-bonds as a new type of gate in $K^{+}$channel}

Oliver Rauh ${ }^{1}$, Martin Urban ${ }^{2}$, Leonhard M. Henkes ${ }^{2}$, Tobias Winterstein ${ }^{1}$, Timo Greiner ${ }^{1}$, James L. Van Etten ${ }^{3}$, Anna Moroni ${ }^{4}$, Stefan M. Kast ${ }^{2}$, Gerhard Thiel ${ }^{1 *}$, Indra Schroeder ${ }^{1}$

${ }^{1}$ Plant Membrane Biophysics, Technical University Darmstadt, Darmstadt, Germany, ${ }^{2}$ Physikalische Chemie III, Technische Universität Dortmund, Dortmund, Germany, ${ }^{3}$ Department of Plant Pathology and Nebraska Center for Virology, University of Nebraska Lincoln, Lincoln, Nebraska, United States 68583-0900, ${ }^{4}$ Department of Biosciences and CNR IBF-Mi, Università degli Studi di Milano, Milano, Italy

* Corresponding author E-mail: thiel@bio.tu-darmstadt.de

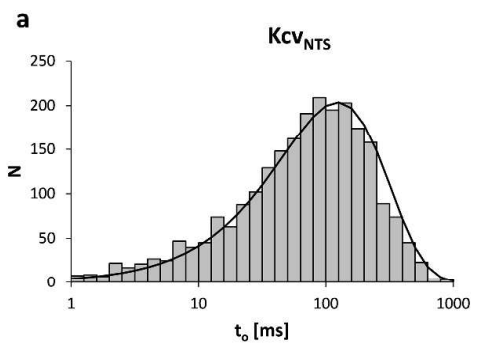

c

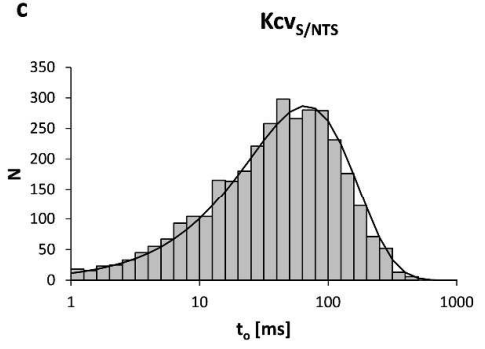

e
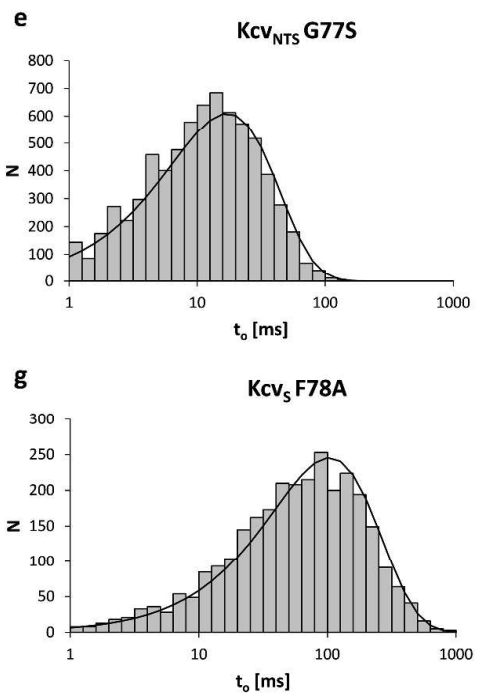

b

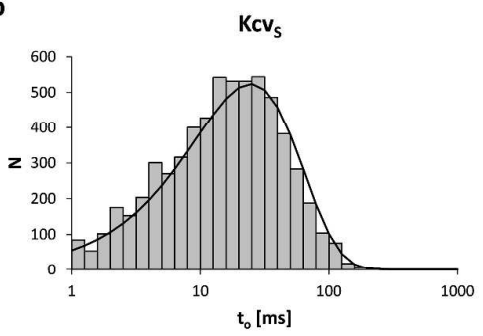

d
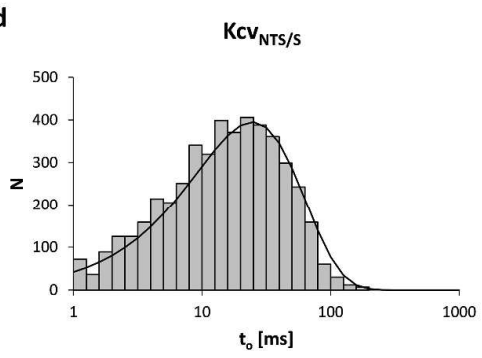

f

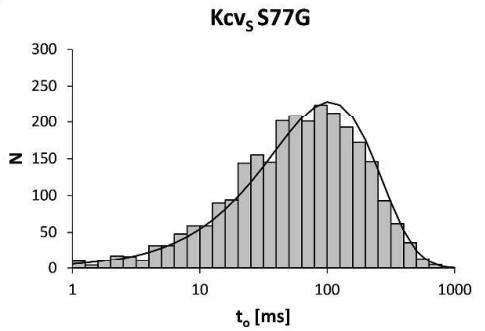

h

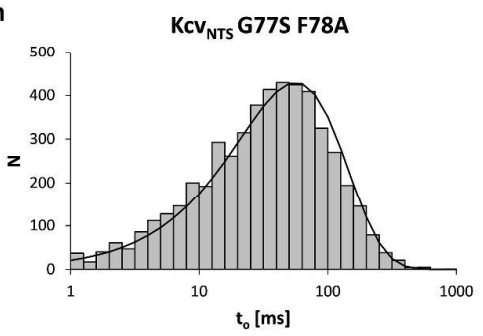

\section{Supplementary Figure 1.}

\section{Open dwell times of Kcv channels}

Dwell time histograms from recordings at $+120 \mathrm{mV}$ for $\mathrm{KcV}_{\mathrm{NTS}}, \mathrm{KcV}_{\mathrm{S}}$ and chimeras/ mutants. All open dwell time histograms can be fitted with a single exponential. 
a

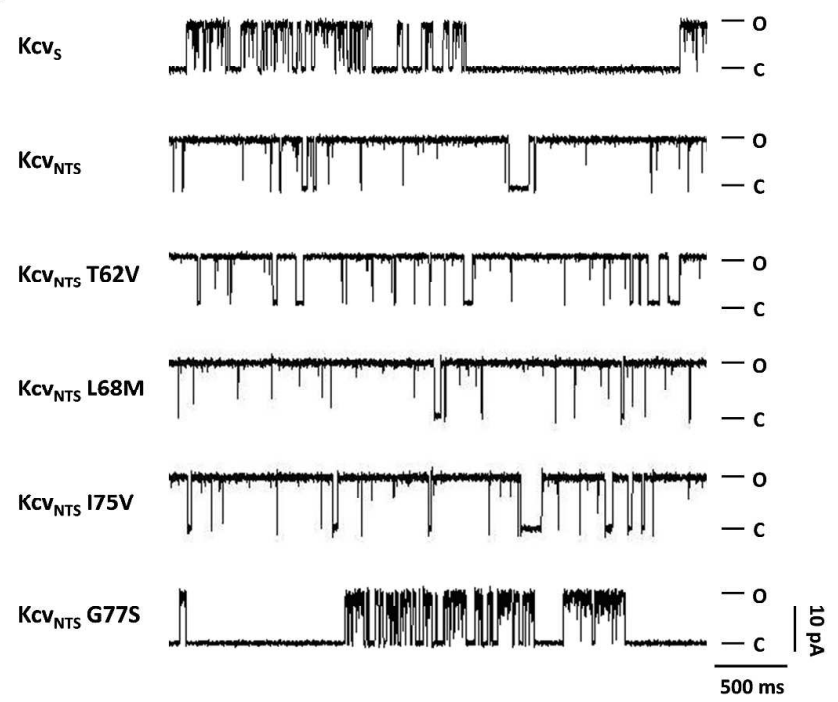

b

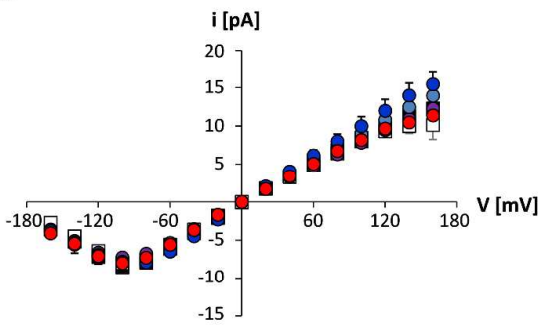

C

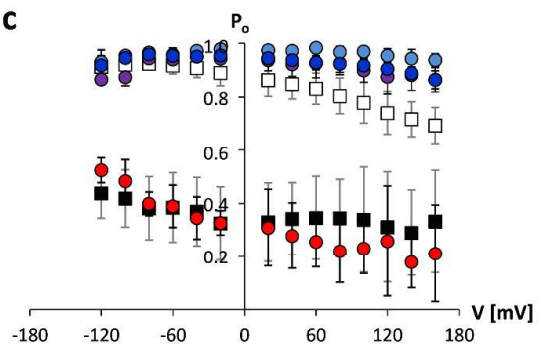

\section{Supplementary Figure 2.}

Only the exchange $\mathrm{G} 77 \mathrm{~S}$ in $\mathrm{KCV}_{\mathrm{NTS}}$ results in the electrophysiological phenotype of Kcvs.

To identify the relevant AA in TMD2 for gating we mutated all 4 candidates in KcV $\mathrm{NTS}_{\mathrm{N}}$ into the respective residue of $\mathrm{Kcv}_{\mathrm{S}}$. (a) Characteristic single channel fluctuations of the wt channels $\mathrm{KcV}_{\mathrm{S}}$ and $\mathrm{KcV}_{\mathrm{NTS}}$ as well as the $\mathrm{KcV}_{\mathrm{NTS}}$ mutants T62V, L68M, I75V and G77S at $+120 \mathrm{mV}$ in planar DPhPC bilayers. (b) Mean single channel $\mathrm{i} / \mathrm{V}$ relations $( \pm s d)$ and $(\mathbf{c})$ mean open probabilities ( $\pm s d$ ) of $K_{c v_{N T S}}$ (open squares, $n=$ 6), $\mathrm{KcV}_{\mathrm{S}}$ (filled squares, $\mathrm{n}=9$ ), $\mathrm{KcV}_{\mathrm{NTS}} \mathrm{T62V}$ (purple circles, $\mathrm{n}=4$ ), $\mathrm{KcV}_{\mathrm{NTS}} \mathrm{L68M}$ (light blue circles, $n=3$ ), $\mathrm{KcV}_{\mathrm{NTS}} 175 \mathrm{~V}$ (blue circles, $\mathrm{n}=4$ ) and $\mathrm{KcV}_{\mathrm{NTS}} \mathrm{G} 77 \mathrm{~S}$ (red circles, $\mathrm{n}$ $=5)$. 
a

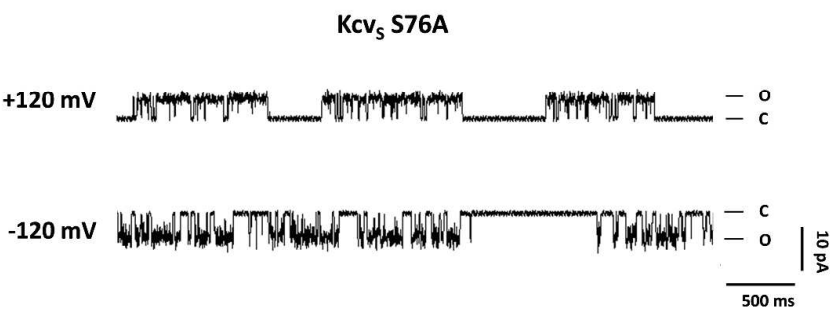

b

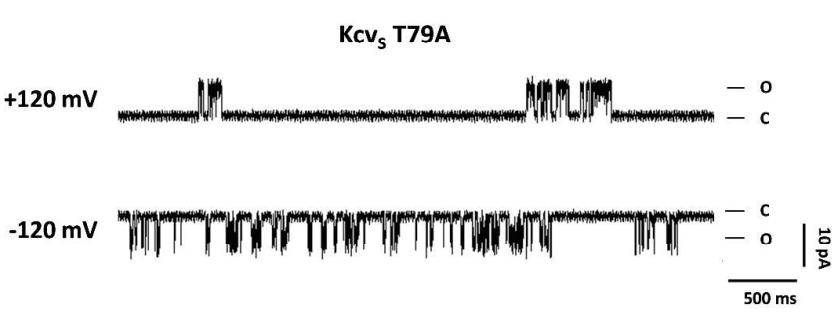

c

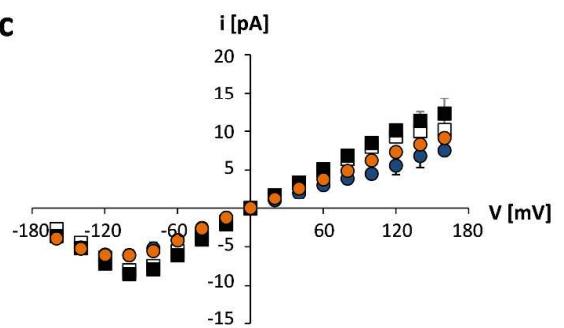

d

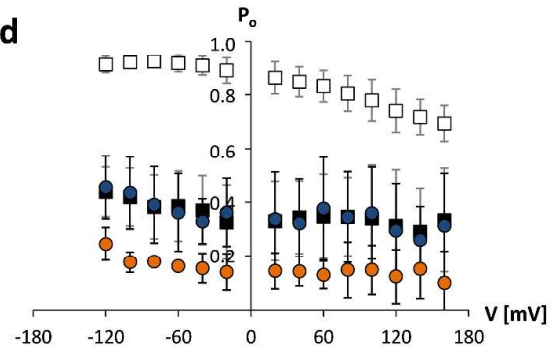

\section{Supplementary Figure 3.}

AAs $\mathrm{S} 76$ and T79 in $\mathrm{Kcv}_{\mathrm{S}}$ do not contribute to the long lived closed time.

Characteristic single channel fluctuations of mutant $\mathrm{Kcv}_{\mathrm{S}} \mathrm{S} 76 \mathrm{~A}$ (a) and Kcv $\mathrm{K}$ T79A (b) at $+/-120 \mathrm{mV}$ in planar lipid bilayers. (c) Mean single channel i/V relations ( $\pm \mathrm{sd}$ ) and (d) mean open probabilities ( $\pm \mathrm{sd}$ ) of $\mathrm{KcV}_{\mathrm{NTS}}$ (open squares), $\mathrm{KcV}_{\mathrm{S}}$ (filled squares), $\mathrm{Kcv}_{\mathrm{S}}$ T79A (orange circles, $\mathrm{n}=4$ ) and $\mathrm{Kcv}_{\mathrm{S}}$ S76A F78A (blue circles, $\mathrm{n}=3$ ). 


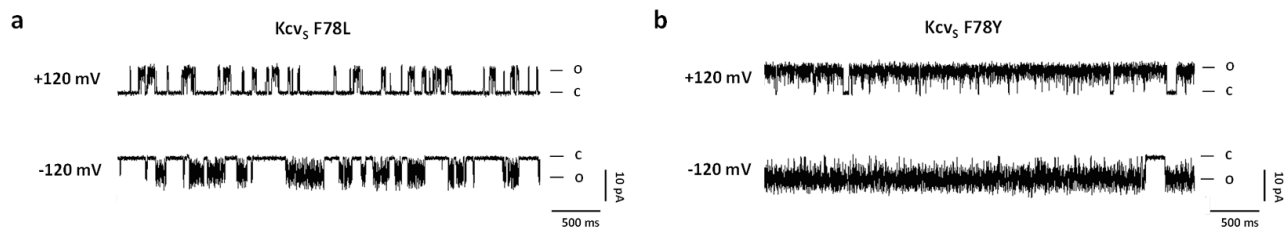

C

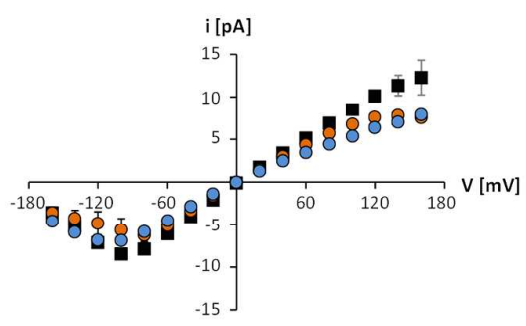

e

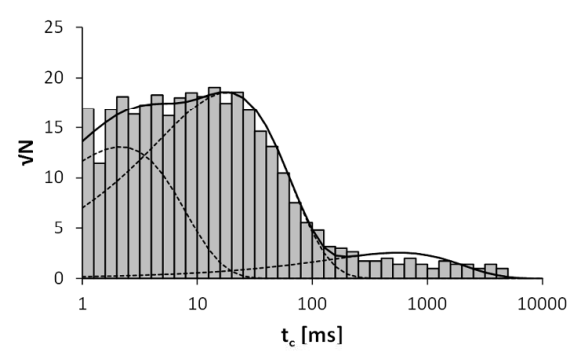

d

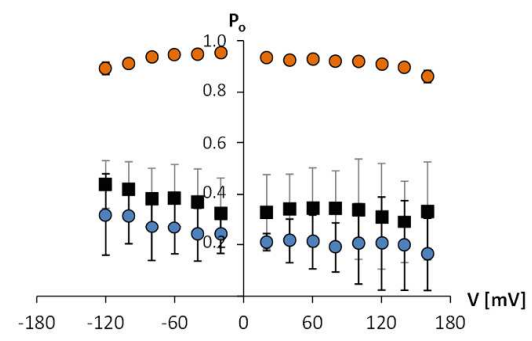

$\mathbf{f}$
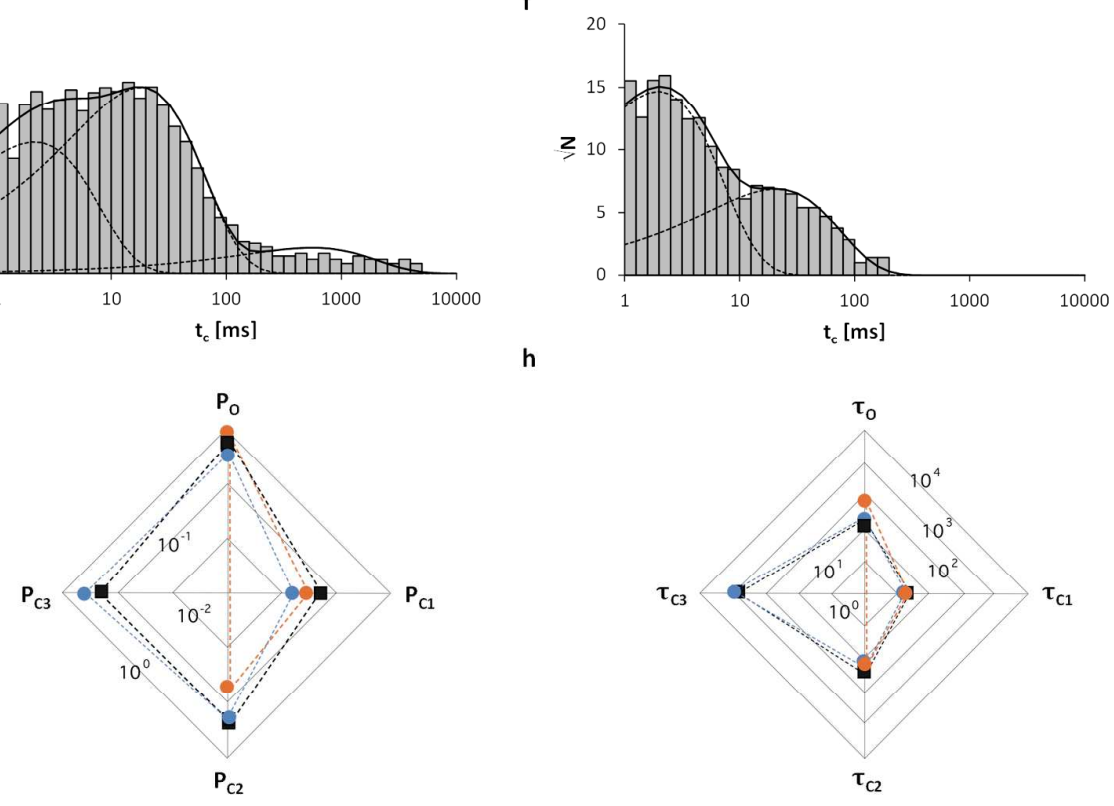

\section{Supplementary Figure 4.}

The gating function of the aromatic side chain of F78 can be substituted by the hydrophobic AA Leu but not by the aromatic side chain of Tyr.

Characteristic single channel fluctuations of mutant Kcvs F78L (a) and Kcvs F78Y (b) at $+/-120 \mathrm{mV}$ in planar lipid bilayers. (c) Mean single channel i/V relations ( $\pm \mathrm{sd}$ ) and (d) mean open probabilities ( $\pm \mathrm{sd}$ ) of $\mathrm{Kcv}_{\mathrm{S}}$ (filled squares), $\mathrm{Kcv}_{\mathrm{s}} \mathrm{F78Y}$ (orange circles, $\mathrm{n}=3$ ) and $\mathrm{Kcv}_{\mathrm{S}} \mathrm{F} 78 \mathrm{~L}$ (blue circles, $\mathrm{n}=3$ ). Exemplary closed dwell times at $+120 \mathrm{mV}$ for $\mathrm{Kcv}_{S} \mathrm{~F} 78 \mathrm{~L}$ (e) and $\mathrm{Kcv}_{S} \mathrm{~F} 78 \mathrm{Y}$ (f). The data in F can be fitted with two exponentials while the data in E require a third exponential. (g) Probabilities $(P)$ of the wt channel and mutants for occupying the open state $(\mathrm{O})$ and the closed states (C1-C3) and mean lifetimes (in ms) of the open state $\left(\tau_{0}\right)$ and of the three closed states $\left(\tau_{c 1}-\tau_{c 3}\right)$ (h). The probabilities of occupancy and mean lifetimes were calculated from three independent $5 \mathrm{~min}$ recordings. The symbols in $\mathrm{d}, \mathrm{g}$ and $\mathrm{h}$ correspond to those in $\mathrm{c}$. 


\section{F78-1}

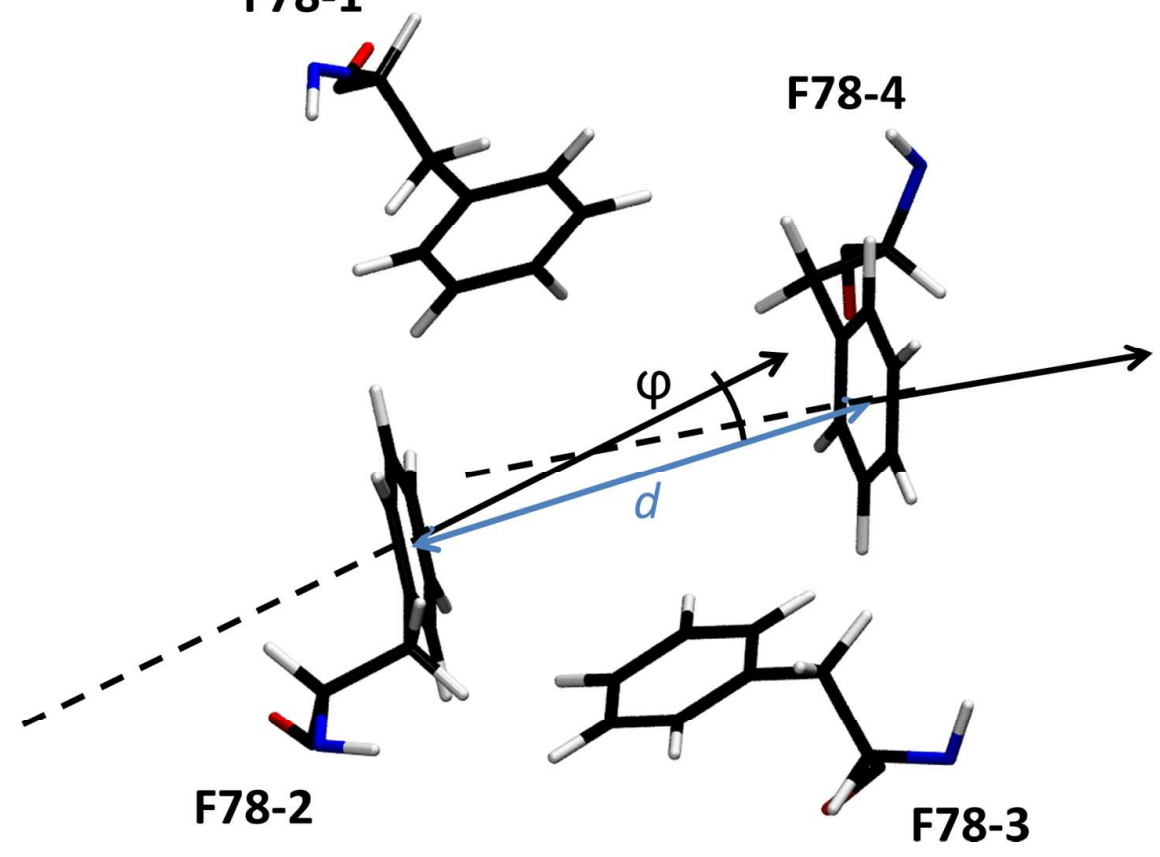

\section{Supplementary Figure 5.}

Definition of distance-angle pairs of $\mathrm{F} 77$ in $\mathrm{KcV}_{\mathrm{NTS}}$ and $\mathrm{Kcv}_{\mathrm{S}}$ tetramers. The image illustrates the geometric criteria with distance $d$ and angle $\varphi$ for characterizing $\pi$ stack geometries in Fig. 7. 

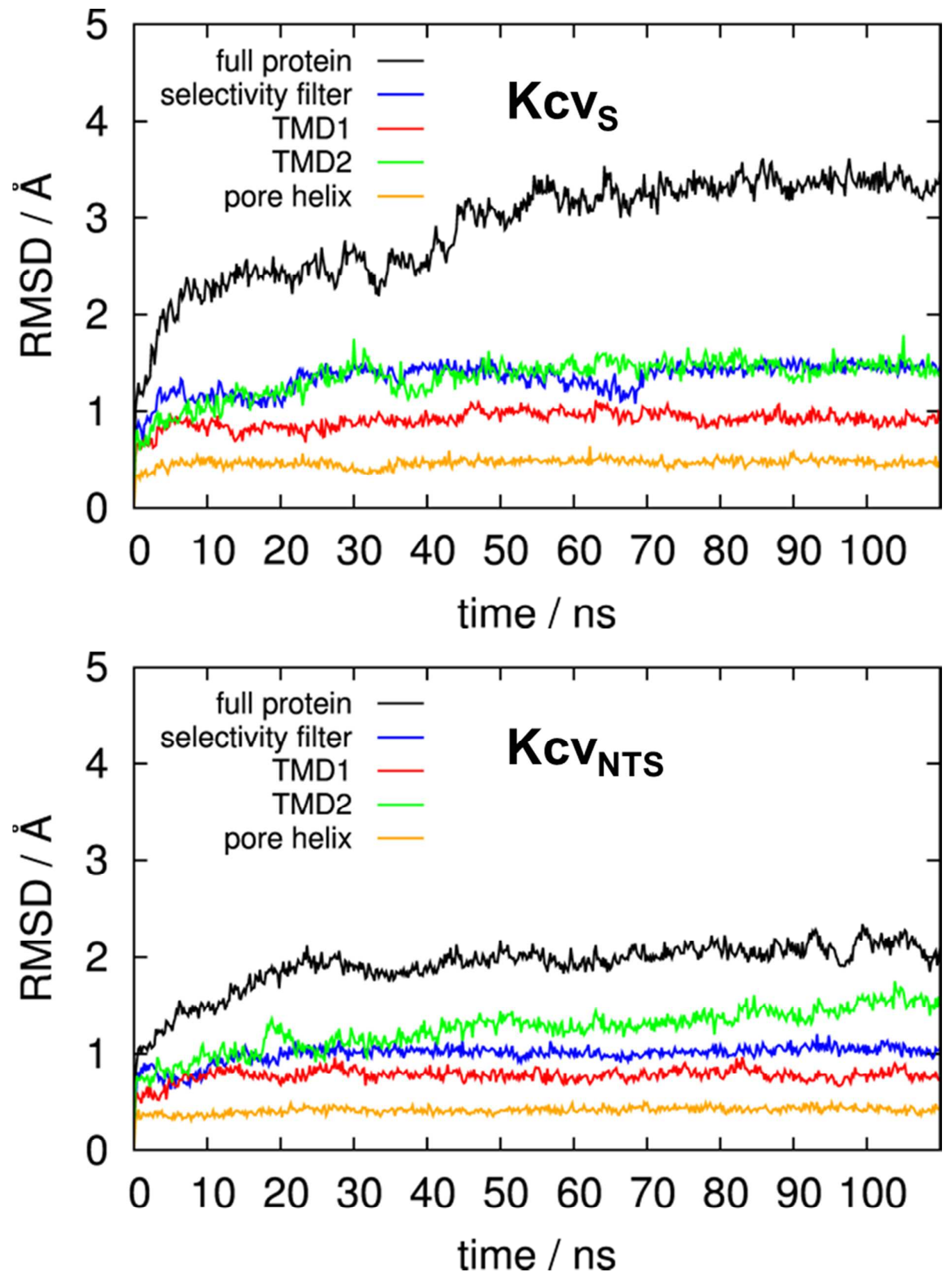

\section{Supplementary Figure 6.}

Demonstration of MD simulation stability for $\mathrm{Kcv}_{\mathrm{S}}$ (top) and $\mathrm{KcV}_{\mathrm{NTS}}$ (bottom) models as measured by the root mean square deviations (RMSD) for various protein structure components with respect to the start of production runs. 


\begin{tabular}{|c|c|c|c|c|c|c|c|c|}
\hline & $\tau_{0} / \mathrm{ms}$ & $\tau_{\mathrm{C} 1} / \mathrm{ms}$ & $\tau_{\mathrm{C} 2} / \mathrm{ms}$ & $\tau_{\mathrm{c} 3} / \mathrm{ms}$ & $P_{0}$ & $\mathbf{P}_{\mathrm{C1}}$ & $\mathbf{P}_{\mathrm{C2}}$ & $P_{C 3}$ \\
\hline $\mathrm{KCV}_{\mathrm{NTS}}$ & $79.1 \pm 18.6$ & $1.3 \pm 0.2$ & $24.0 \pm 3.9$ & - & $0.874 \pm 0.073$ & $0.008 \pm 0.002$ & $0.117 \pm 0.075$ & 0 \\
\hline $\mathrm{KCV}_{\mathrm{S}}$ & $15.1 \pm 2.5$ & $1.8 \pm 0.8$ & $23.8 \pm 9.4$ & $480 \pm 145$ & $0.525 \pm 0.101$ & $0.047 \pm 0.029$ & $0.208 \pm 0.095$ & $0.220 \pm 0.152$ \\
\hline $\mathrm{KCV}_{\mathrm{S} / \mathrm{NTS}}$ & $63.5 \pm 28.4$ & $1.1 \pm 0.5$ & $47.6 \pm 12.2$ & - & $0.704 \pm 0.171$ & $0.008 \pm 0.003$ & $0.252 \pm 0.171$ & 0 \\
\hline $\mathrm{KcV}_{\mathrm{NTS} / \mathrm{s}}$ & $15.4 \pm 6.4$ & $2.1 \pm 1.1$ & $17.0 \pm 3.4$ & $1070 \pm 118$ & $0.227 \pm 0.053$ & $0.018 \pm 0.011$ & $0.109 \pm 0.028$ & $0.647 \pm 0.028$ \\
\hline $\mathrm{Kcv}_{\mathrm{S}} \mathrm{S77G}$ & $79.7 \pm 15.7$ & $1.3 \pm 0.1$ & $28.4 \pm 3.6$ & - & $0.904 \pm 0.029$ & $0.012 \pm 0.004$ & $0.084 \pm 0.031$ & 0 \\
\hline $\mathrm{Kcv}_{\mathrm{NTS}}$ G77S & $11.2 \pm 0.4$ & $1.2 \pm 0.2$ & $15.1 \pm 4.4$ & $354 \pm 220$ & $0.540 \pm 0.032$ & $0.036 \pm 0.007$ & $0.245 \pm 0.035$ & $0.179 \pm 0.074$ \\
\hline $\mathrm{KCV}_{\mathrm{S}}$ F78A & $42.1 \pm 17.2$ & $0.6 \pm 0.1$ & $7.9 \pm 4.2$ & - & $0.971 \pm 0.014$ & $0.014 \pm 0.005$ & $0.015 \pm 0.017$ & 0 \\
\hline $\begin{array}{c}\text { KCv }_{\text {NTS }} \text { G77S } \\
\text { F78A }\end{array}$ & $63.7 \pm 60.1$ & $1.3 \pm 0.5$ & $27.8 \pm 16.5$ & - & $0.926 \pm 0.026$ & $0.026 \pm 0.010$ & $0.051 \pm 0.018$ & 0 \\
\hline $\mathrm{Kcv}_{\mathrm{S}}$ F78L & $21.8 \pm 13.9$ & $1.7 \pm 0.6$ & $13.5 \pm 5.0$ & $983 \pm 419$ & $0.348 \pm 0.126$ & $0.017 \pm 0.011$ & $0.199 \pm 0.171$ & $0.436 \pm 0.305$ \\
\hline $\mathrm{Kcv}_{\mathrm{S}}$ F78Y & $56.4 \pm 6.0$ & $1.9 \pm 0.2$ & $16.9 \pm 2.1$ & - & $0.922 \pm 0.012$ & $0.025 \pm 0.002$ & $0.052 \pm 0.013$ & 0 \\
\hline $\mathrm{Kcv}_{\mathrm{NTS}} \mathrm{F78L}$ & $\begin{array}{c}108.8 \pm \\
16.4\end{array}$ & $1.3 \pm 0.2$ & $27.3 \pm 3.8$ & - & $0.916 \pm 0.024$ & $0.008 \pm 0.001$ & $0.077 \pm 0.024$ & 0 \\
\hline
\end{tabular}

Table S1: Mean lifetimes and probabilities of occupancy of $\mathrm{Kcv}_{\mathrm{NTS}}, \mathrm{Kcv}_{\mathrm{s}}$ and some selected mutants. The probabilities of occupancy $P( \pm s d)$ and mean lifetimes $\tau( \pm s d)$ of the open state $\mathrm{O}$ and the three closed states $\mathrm{C} 1, \mathrm{C} 2$ and $\mathrm{C} 3$ were calculated from three independent 5 min recordings at $+120 \mathrm{mV}$. 